\title{
An optimal-estimation-based aerosol retrieval algorithm using OMI near-UV observations
}

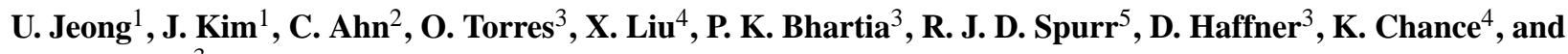 \\ B. N. Holben ${ }^{3}$ \\ ${ }^{1}$ Dept. of Atmospheric Sciences, Yonsei University, Seoul, Korea \\ ${ }^{2}$ Science Systems and Applications, Inc., Lanham, Maryland, USA \\ ${ }^{3}$ Goddard Space Flight Center, NASA, Greenbelt, Maryland, USA \\ ${ }^{4}$ Harvard-Smithsonian Center for Astrophysics, Cambridge, Massachusetts, USA \\ ${ }^{5}$ RT Solutions, Inc., 9 Channing Street, Cambridge, Massachusetts, USA
}

Correspondence to: J. Kim (jkim2@yonsei.ac.kr)

Received: 26 March 2015 - Published in Atmos. Chem. Phys. Discuss.: 18 June 2015

Revised: 27 October 2015 - Accepted: 25 November 2015 - Published: 18 January 2016

\begin{abstract}
An optimal-estimation(OE)-based aerosol retrieval algorithm using the OMI (Ozone Monitoring Instrument) near-ultraviolet observation was developed in this study. The OE-based algorithm has the merit of providing useful estimates of errors simultaneously with the inversion products. Furthermore, instead of using the traditional lookup tables for inversion, it performs online radiative transfer calculations with the VLIDORT (linearized pseudo-spherical vector discrete ordinate radiative transfer code) to eliminate interpolation errors and improve stability. The measurements and inversion products of the Distributed Regional Aerosol Gridded Observation Network campaign in northeast Asia (DRAGON NE-Asia 2012) were used to validate the retrieved aerosol optical thickness (AOT) and single scattering albedo (SSA). The retrieved AOT and SSA at $388 \mathrm{~nm}$ have a correlation with the Aerosol Robotic Network (AERONET) products that is comparable to or better than the correlation with the operational product during the campaign. The OEbased estimated error represented the variance of actual biases of AOT at $388 \mathrm{~nm}$ between the retrieval and AERONET measurements better than the operational error estimates. The forward model parameter errors were analyzed separately for both AOT and SSA retrievals. The surface reflectance at $388 \mathrm{~nm}$, the imaginary part of the refractive index at $354 \mathrm{~nm}$, and the number fine-mode fraction (FMF) were found to be the most important parameters affecting the retrieval accuracy of AOT, while FMF was the most important parameter for the SSA retrieval. The additional information
\end{abstract}

provided with the retrievals, including the estimated error and degrees of freedom, is expected to be valuable for relevant studies. Detailed advantages of using the OE method were described and discussed in this paper.

\section{Introduction}

Anthropogenic aerosols have affected both the radiative and meteorological balance in the atmosphere and thus the radiative forcing of the atmosphere directly and indirectly (Ramanathan et al., 2001; Russell et al., 1999; Breon et al., 2002). To understand the role of aerosol in the atmosphere from a global perspective, reliable aerosol data from satellites are essential (Al-Saadi et al., 2005; Kinne et al., 2006). The several satellite-based aerosol retrieval methods based on multi-wavelength (Levy et al., 2007; Kim et al., 2007), multiangle (Fisher et al., 2014), active light (Young et al., 2013), and polarization (Deuze et al., 2001) measurements have their own advantages and limitations. The inversion products from such measurements provide various parameters of aerosols at different channels. Thus, appropriate sources of aerosol information need to be employed for relevant studies.

An important advantage of using the ultraviolet (UV) channel to retrieve aerosol optical properties is that the results are less affected by uncertainties in surface reflectance (Torres et al., 1998). The retrieved aerosol products have 
relatively uniform quality over both land and ocean except over ice-snow surfaces (Torres et al., 2007; Herman et al., 1997). The near-UV technique for aerosol remote sensing has the additional merit of a long-term data record including aerosol absorption properties of over 30 years starting from the launch of the Total Ozone Mapping Spectrometer (TOMS) on Nimbus-7 in 1978 (Torres et al., 1998, 2002a, 2005). Thus, the retrieved products using the near-UV technique from TOMS and Ozone Monitoring Instrument (OMI) measurements are appropriate for climatological research (Torres et al., 2002b, 2007). Information on aerosol extinction and absorption properties in the UV region is also important for estimating the air mass factor (AMF) for trace gas retrievals (Palmer et al., 2001; Lin et al., 2014). However, deriving information on aerosol using available hyperspectral measurements such as OMI and Global Ozone Monitoring Experiment (GOME) is quite challenging due to the relatively low spatial resolution compared to typical imagers. Thus, the error estimates of retrievals using such sensors are particularly important to understand the reliability of the information, so that it can be used appropriately. The main objective of this study is to improve the applicability of the aerosol inversion products of OMI by providing the reliable error estimates of the retrievals.

Accuracy assessments of the retrieved aerosol optical properties using UV radiances have been performed by comparison with results from reference methods including ground-, airborne-, and satellite-based remote sensing techniques (Torres et al., 2005; Jethva et al., 2014; Torres et al., 2002a; Ahn et al., 2014; Livingston et al., 2009; Ahn et al., 2008; Curier et al., 2008). The aerosol information content of selected OMI spectral radiances using a multiwavelength algorithm has been estimated using principal component analysis for simulated radiances (Veihelmann et al., 2007). Uncertainty estimates of UV aerosol retrievals have also been calculated by perturbation analysis (Torres et al., 1998, 2002b). Inversion algorithms based on optimal estimation (OE) theory provide not only a constrained solution with respect to the a priori information but also detailed error analysis from well-categorized error sources (Rodgers, 2000). In addition, iterative inversion methods such as OE provide additional retrieval masking parameters (e.g., cost function and convergence criteria). Recently developed OEbased retrieval methods have provided both improved inversion products and error estimates from the aerosol and surface error sources (Wagner et al., 2010; Govaerts et al., 2010; Wurl et al., 2010).

A large amount of aerosol is emitted from both natural and anthropogenic sources in east Asia (Lee et al., 2012). The spatial and temporal variations in aerosol optical properties are significant because of the diverse emission sources and trans-boundary transport (Jeong et al., 2011). Thus, the assumed aerosol inversion parameters may cause substantial uncertainties in the retrieval. However, there are insufficient ground-based measurements of aerosol op- tical properties with suitable spatial and temporal coverage in east Asia, despite their importance for global air quality and climate change. The Distributed Regional Aerosol Gridded Observation Network Northeast Asia (DRAGONNE Asia) 2012 campaign (http://aeronet.gsfc.nasa.gov/new web/DRAGON-Asia_2012_Japan_South_Korea.html) provides valuable data sets including both urban and regionalscale observations at more than 40 sites in northeast Asia. In the present study, an OE-based near-UV aerosol retrieval and error analysis algorithm is developed to provide both improved aerosol inversion products and estimates of their uncertainties. The retrieved aerosol products and estimated uncertainties are validated against the DRAGON-NE Asia 2012 campaign measurements.

\section{Data}

OMI is a nadir-viewing hyperspectral spectrometer aboard the EOS (Earth Observing System)-Aura spacecraft that measures upwelling radiances from the top of the atmosphere in the ultraviolet and visible $(270-500 \mathrm{~nm})$ regions with an approximate spectral resolution of $0.5 \mathrm{~nm}$ (Levelt et al., 2006). The advantage of using OMI for aerosol retrieval is its higher spatial resolution than other UV hyperspectral spectrometers (from $13 \times 24 \mathrm{~km}^{2}$ at nadir to $28 \times 150 \mathrm{~km}^{2}$ at the swath extremes with median pixel size $15 \times 32 \mathrm{~km}^{2}$ ) together with its $2600 \mathrm{~km}$ wide swath. The radiometric calibration procedure and the estimated accuracy of OMI are described in Dobber et al. (2006). To determine aerosol type and vertical distribution, the current OMI near-UV aerosol algorithm (OMAERUV) employs the Cloud-Aerosol Lidar with Orthogonal Polarization (CALIOP) monthly climatology of aerosol layer height and real-time Atmospheric Infrared Sounder (AIRS) carbon monoxide (CO) observations (Torres et al., 2013). Surface reflectances at 354 and $388 \mathrm{~nm}$ were assumed to be Lambertian and were taken from the TOMS climatology database. Aerosol vertical distribution and surface reflectance information identical to that used in the operational algorithm were used for the OE-based algorithm here.

In this study, the spatial and temporal domains for analysis were confined to the DRAGON-NE Asia 2012 campaign as shown in Fig. 1 and Table 1. The gridded observation networks had high spatial resolution over the representative megacities in northeast Asia: Seoul in South Korea and Osaka in Japan. To validate and compare the retrieved aerosol products from OMI, level 2 campaign products were used from the Aerosol Robotic Network (AERONET): $380 \mathrm{~nm}$ aerosol optical thickness (AOT) from direct sun measurements, and spectral single scattering albedo (SSA) from almucantar inversion products (Holben et al., 1998; Dubovik and King, 2000; Dubovik et al., 2000, 2006). Retrieved $388 \mathrm{~nm}$ AOT from OMI was validated against AERONET $380 \mathrm{~nm}$ AOT. The OMI AOT retrievals were averaged within 

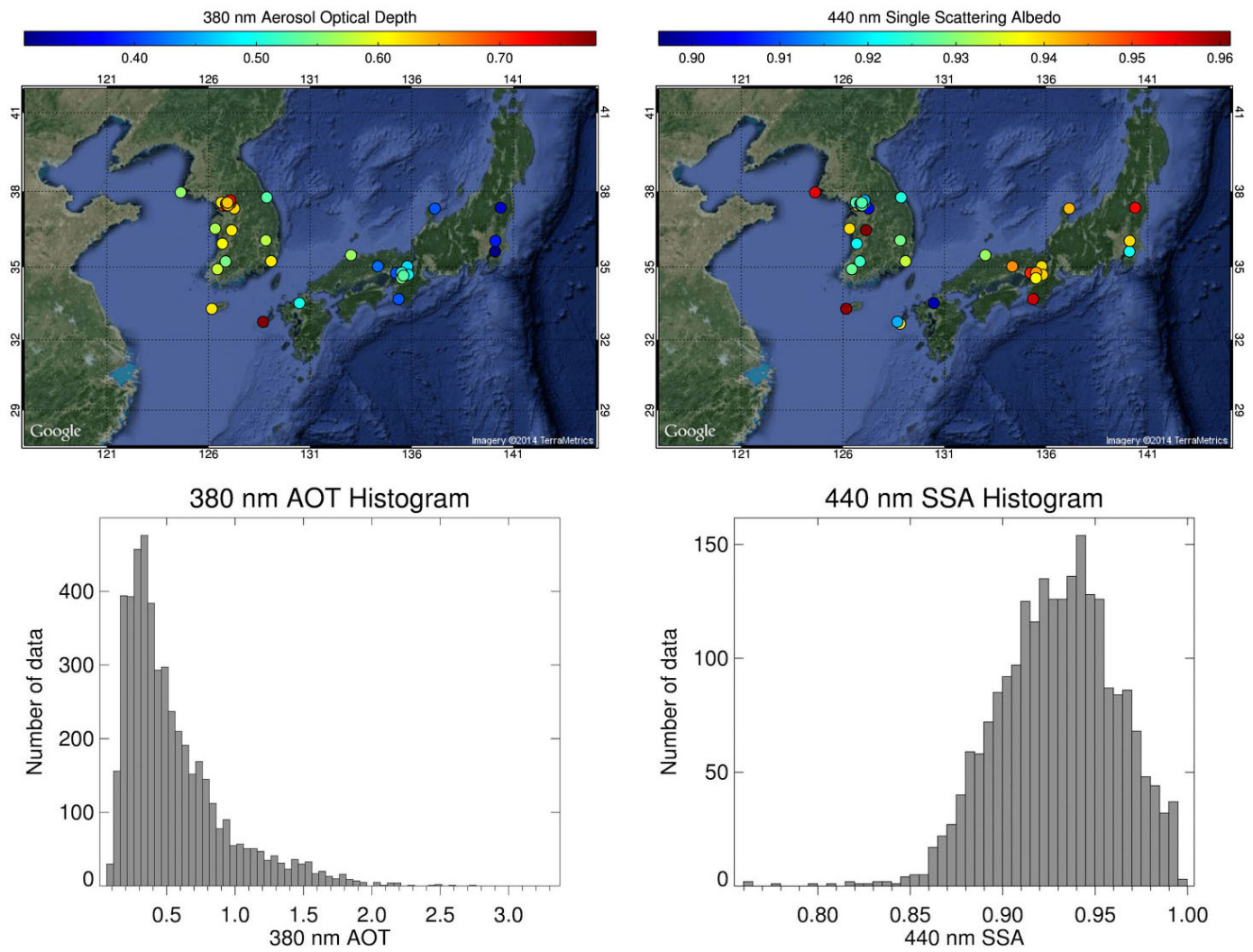

Figure 1. Mean $380 \mathrm{~nm}$ aerosol optical thickness (AOT) and $440 \mathrm{~nm}$ single scattering albedo and their probability density functions during the DRAGON-NE Asia 2012 campaign.

a radius of $0.5^{\circ}$ of the AERONET site and within $\pm 30 \mathrm{~min}$ of the OMI overpass time (about 13:40 local time). The resulting OMI AOT average values were then compared with the time-averaged Sun photometer measurements.

Aerosol absorption properties are retrieved at different wavelengths by AERONET and OMI. The AERONET inversion products of the SSA are available at 440,670, 860, and $1020 \mathrm{~nm}$, while the OMAERUV algorithm retrieves the SSA at 354 and $388 \mathrm{~nm}$. Earlier field studies found that aerosol absorption is a continuous function of wavelength in the ultraviolet to short-infrared region (Kirchstetter et al., 2004; Russell et al., 2010). To compare the SSA values from OMI and AERONET at the same wavelength, the AERONET SSA at $388 \mathrm{~nm}$ was obtained by extrapolating the SSAs at $440-1020 \mathrm{~nm}$ using a spline function. Then the converted AERONET SSA at $388 \mathrm{~nm}$ was compared with the retrieved OMI SSA values even though uncertainties might exist in the transformation. Unlike the direct sun measurements including AOT, the inversion products of AERONET from almucantar measurements are retrieved less frequently and require appropriate atmospheric conditions for AOT $(440 \mathrm{~nm}$ AOT $>0.4$ ) and solar zenith angle (solar zenith angle $>45^{\circ}$ ) (Dubovik and King, 2000; Jethva et al., 2014). Such favorable atmospheric conditions for the inversion using almucantar measurements rarely overlap closely with the OMI over- pass time. Furthermore, too narrow a time window around the satellite overpass time reduces the number of comparison samples. In this study, to secure enough data points, the SSA of a region at OMI overpass time was assumed to adequately represent the daily values. For the comparison, the converted $388 \mathrm{~nm}$ SSA from AERONET was averaged over a day and the OMI retrievals of $388 \mathrm{~nm}$ SSA were spatially averaged over a grid area of $0.5^{\circ} \times 0.5^{\circ}$ centered on the AERONET site.

\section{Method}

\subsection{Operational OMI near-UV aerosol algorithm}

The OMAERUV uses two channel radiances at 354 and $388 \mathrm{~nm}$ to estimate aerosol amount and absorption properties (Torres et al., 1998, 2007, 2013). AOT and SSA at $388 \mathrm{~nm}$ are retrieved from precalculated reflectance lookup tables (LUT) for predetermined nodal points of observational geometry and aerosol optical properties, total optical depth, and aerosol layer height. Three major aerosol types are considered and listed in Table 2: desert dust, carbonaceous aerosols associated with biomass burning, and weakly absorbing sulfate-based aerosols (hereafter dust, smoke, and 
Table 1. Positions and mean AOT and SSA at $388 \mathrm{~nm}$ of the AERONET sites during the DRAGON-NE Asia 2012 campaign.

\begin{tabular}{|c|c|c|c|c|}
\hline Site name & $\begin{array}{r}\text { Latitude }\left(^{\circ}\right) \\
(\text { north) }\end{array}$ & $\begin{array}{r}\text { Longitude }\left(^{\circ}\right) \\
(\text { east })\end{array}$ & $\begin{array}{r}\text { Mean } 380 \mathrm{~nm} \\
\text { AOT }\end{array}$ & $\begin{array}{r}\text { Mean } 440 \mathrm{~nm} \\
\mathrm{SSA}\end{array}$ \\
\hline Baengnyeong & 37.97 & 124.63 & 0.56 & 0.96 \\
\hline Yonsei University, Seoul & 37.56 & 126.94 & 0.63 & 0.93 \\
\hline Anmyeon & 36.54 & 126.33 & 0.57 & 0.94 \\
\hline Bokjeong, Seoul & 37.46 & 127.13 & 0.75 & 0.90 \\
\hline Gangneung-Wonju National University & 37.77 & 128.87 & 0.53 & 0.92 \\
\hline Guwol, Seoul & 37.45 & 126.72 & 0.69 & 0.94 \\
\hline GIST, Gwangju & 35.23 & 126.84 & 0.54 & 0.93 \\
\hline HUFS, Yongin & 37.34 & 127.27 & 0.63 & 0.90 \\
\hline Kongju National University, Gongju & 36.47 & 127.14 & 0.62 & 0.96 \\
\hline Konkuk University, Seoul & 37.54 & 127.08 & 0.67 & 0.92 \\
\hline Korea University, Seoul & 37.59 & 127.03 & 0.73 & 0.92 \\
\hline Kunsan National University, Gunsan & 35.94 & 126.68 & 0.61 & 0.92 \\
\hline Kyungil University, Gyeongsan & 36.07 & 128.82 & 0.57 & 0.93 \\
\hline Mokpo National University, Mokpo & 34.91 & 126.44 & 0.58 & 0.93 \\
\hline NIER, Incheon & 37.57 & 126.64 & 0.62 & 0.93 \\
\hline Pusan National University, Pusan & 35.24 & 129.08 & 0.62 & 0.93 \\
\hline Sanggye, Seoul & 37.66 & 127.07 & 0.73 & 0.92 \\
\hline Sinjeong, Seoul & 37.52 & 126.86 & 0.64 & 0.91 \\
\hline Soha, Seoul & 37.45 & 126.89 & 0.69 & 0.91 \\
\hline Gosan, Jeju & 33.29 & 126.16 & 0.62 & 0.96 \\
\hline Seoul National University, Seoul & 37.46 & 126.95 & 0.65 & 0.93 \\
\hline Fukuoka & 33.52 & 130.48 & 0.50 & 0.90 \\
\hline Kōriyama & 37.36 & 140.38 & 0.34 & 0.95 \\
\hline Kyoto & 35.03 & 135.78 & 0.47 & 0.94 \\
\hline Matsue & 35.48 & 133.01 & 0.56 & 0.93 \\
\hline Mt. Ikoma & 34.68 & 135.68 & 0.39 & 0.96 \\
\hline Mt. Rokkō & 34.76 & 135.23 & 0.41 & 0.95 \\
\hline Nara & 34.69 & 135.83 & 0.48 & 0.94 \\
\hline Nishi-Harima & 35.03 & 134.34 & 0.42 & 0.95 \\
\hline North Osaka & 34.77 & 135.51 & 0.52 & 0.94 \\
\hline South Osaka & 34.54 & 135.50 & 0.55 & 0.94 \\
\hline Tsukuba & 36.05 & 140.12 & 0.38 & 0.94 \\
\hline Noto & 37.33 & 137.14 & 0.41 & 0.94 \\
\hline Shirahama & 33.69 & 135.36 & 0.41 & 0.96 \\
\hline Chiba University & 35.63 & 140.10 & 0.31 & 0.92 \\
\hline Fukue & 32.75 & 128.68 & 0.78 & 0.92 \\
\hline
\end{tabular}

Table 2. Aerosol number-size distribution parameters* and real refractive index $\left(n_{\mathrm{r}}\right)$ for each aerosol type in the OMI near-UV algorithm.

\begin{tabular}{lrrrrrrr}
\hline Aerosol model & $r_{g} \mathrm{~m} 1(\mu \mathrm{m})$ & $r_{g} \mathrm{~m} 2(\mu \mathrm{m})$ & $\sigma \mathrm{m} 1(\mu \mathrm{m})$ & $\sigma \mathrm{m} 2(\mu \mathrm{m})$ & FMF & $n_{\mathrm{r}}$ & $n_{\mathrm{i}, 354 / 388}$ \\
\hline Sulfate & 0.088 & 0.509 & 1.499 & 2.160 & 0.999596 & 1.40 & 1.0 \\
Smoke & 0.080 & 0.705 & 1.492 & 2.075 & 0.999795 & 1.50 & 1.2 \\
Dust & 0.052 & 0.670 & 1.697 & 1.806 & 0.995650 & 1.55 & 1.4 \\
\hline
\end{tabular}

* Number-weighted particle size distribution parameters: fine and coarse-mode radii $\left(r_{g} \mathrm{~m} 1\right.$ and $\left.r_{g} \mathrm{~m} 2\right)$ and variance $(\sigma \mathrm{m} 1$ and $\sigma \mathrm{m} 2)$, number fine-mode fraction (FMF).

sulfate, respectively). Each aerosol type has an assumed particle size distribution (PSD) derived from the long-term statistics of AERONET inversion products. The UV real refractive index $\left(n_{\mathrm{r}}\right)$ is obtained from the Optical Properties Of Aerosols And Clouds (OPAC) database (Hess et al., 1998).
In the operational algorithm, the imaginary refractive indices $\left(n_{\mathrm{i}}\right)$ at $354 \mathrm{~nm}$ are assumed to be $1.0,1.2$, and 1.4 times the retrieved $n_{\mathrm{i}}$ at $388 \mathrm{~nm}$ for sulfate, smoke, and dust aerosol, respectively (Torres et al., 2007; Jethva and Torres, 2011). 
Table 3. Retrieval approach criteria of OMI near-UV algorithm version 1.5.3.

\begin{tabular}{|c|c|c|c|c|c|}
\hline $\begin{array}{l}\text { Surface } \\
\text { category }\end{array}$ & UVAI & $\begin{array}{l}\mathrm{CO} \\
\left(10^{18} \text { molecules } \mathrm{cm}^{-2}\right)\end{array}$ & $\begin{array}{l}\text { Surface } \\
\text { type }\end{array}$ & $\begin{array}{l}\text { Aerosol } \\
\text { type }\end{array}$ & $\begin{array}{l}\text { Retrieval } \\
\text { approach }\end{array}$ \\
\hline Ocean & $\geq 0.5$ & $>2.2 \mathrm{NH}(1.8 \mathrm{SH})$ & $\mathrm{NA}^{*}$ & Smoke & Two-channel \\
\hline Ocean & $\geq 0.5$ & $\leq 2.2 \mathrm{NH}(1.8 \mathrm{SH})$ & NA & Dust & Two-channel \\
\hline Ocean & $<0.5$ & - & - & - & No retrieval \\
\hline Land & $\geq 0.5$ & $>2.2 \mathrm{NH}(1.8 \mathrm{SH})$ & All & Smoke & Two-channel \\
\hline Land & $\geq 0.5$ & $\leq 2.2 \mathrm{NH}(1.8 \mathrm{SH})$ & All & Dust & Two-channel \\
\hline Land & $<0.5$ & $>2.2 \mathrm{NH}(1.8 \mathrm{SH})$ & All & Sulfate & Two-channel \\
\hline Land & $<0.5$ & $\leq 2.2 \mathrm{NH}(1.8 \mathrm{SH})$ & All but arid & Sulfate & Single-channel \\
\hline Land & $<0.5$ & $\leq 2.2 \mathrm{NH}(1.8 \mathrm{SH})$ & Arid & Dust & Single-channel \\
\hline
\end{tabular}

* NA: not available.

The overall concept and design of the improved OMAERUV algorithm is well described by Torres et al. (2013).

There have been further improvements at updated OMAERUV (version 1.5.3), which was used for reprocessing the data of AOT and SSA in this study. The OMAERUV algorithm was refined by adjusting thresholds of UV aerosol index (UVAI) and Atmospheric Infrared Sounder (AIRS) CO data in determining aerosol types and retrieval approaches. A cloud-screening scheme in assigning algorithm quality flags was also modified for retaining more good retrievals of carbonaceous and sulfate-type aerosols when the $\mathrm{CO}$ level is high enough (higher than $3.2 \times 10^{18}$ molecules $\mathrm{cm}^{-2}$ ) with various reflectivity thresholds. The UVAI threshold was changed from 0.8 to 0.5 over the oceans. This modification eliminates the land-ocean discontinuity in the UVAI threshold. It is now identical (0.5) for both conditions. The current characterization of ocean reflective properties in the OMAERUV algorithm does not explicitly account for ocean color effects and, therefore, the quality of the retrieved aerosol properties over the oceans for low aerosol amounts would be highly uncertain. For that reason, retrievals over the oceans are only carried out for high concentrations of either desert dust or carbonaceous aerosols as indicated by UVAI values larger than or equal to 0.5 .

Depending on the magnitude of the UVAI and CO parameters as well as the aerosol type, two retrieval approaches are currently used. They are referred to as twochannel and single-channel retrievals. In the two-channel approach, observations at 354 and $388 \mathrm{~nm}$ are used to simultaneously derive AOD and SSA. The single-channel retrieval is applied over scenes when the aerosol absorption signal is low. AOD is retrieved from the $388 \mathrm{~nm}$ observation assuming a value of 1.0 for SSA. Different CO threshold values are used for the northern and southern hemispheres to remove upper tropospheric $\mathrm{CO}$ which may not necessarily be associated with carbonaceous aerosols. A smoothing function in $\mathrm{CO}$ is used to transition from $\mathrm{SH}$ to $\mathrm{NH}$ threshold values. Specific criteria for retrieval approaches are summarized in Table 3. More detailed infor- mation of the latest update in OMAERUV is available from the Readme file on the website (http://disc.sci.gsfc.nasa.gov/ Aura/data-holdings/OMI/omaeruv_v003.shtml).

\subsection{OE-based OMI near-UV aerosol algorithm}

The traditional LUT-based inversion method potentially includes errors due to interpolation between the nodal points and the local minimum, despite its high numerical efficiency. Such interpolation error typically depends on the interpolation method, number of the nodal points, and analytic characteristics of the parameters in LUT. In order to reduce the interpolation error, a higher resolution of the LUT nodal points is necessary which requires a larger amount of numerical computation. Furthermore, in order to modify the retrieval algorithm, the whole LUT should be recalculated even for a small number of target retrievals. The errors from the interpolation are also hard to evaluate as the LUT becomes more complicated.

On the contrary, online retrieval methods can reduce such errors from the interpolation and are numerically efficient particularly for the smaller number of target retrievals. Thus, an online retrieval method is appropriate for the research since retrieval sensitivity studies typically use a smaller number of samples compared to that used in the operation and prefer rapid and accurate results. In our experience, the online retrieval method was numerically more efficient compared to the LUT-based retrieval method by an order of 1 or 2 for less than a few thousand retrievals. Furthermore, online retrieval methods are optimized to avoid local minima by employing additional constraints to find more reliable and stable solutions (Kalman, 1960; Phillips, 1962; Tikhonov, 1963; Twomey, 1963; Chahine, 1968). However, employing an online calculation as the operational retrieval method requires a large computation cost. Thus, using the online calculation for benchmark results for the LUT-based algorithm is recommended to develop the optimized LUT for this operation. Recent efforts to minimize the numerical cost of the radiative transfer model and to increase the calculation speed are 
expected to make the online calculation more practical, even for this operation.

Optimization for measurement error, the inclusion of a priori and ancillary data, and employing physical constraints (e.g., non-negativity of measurements and retrievals) for an inversion method are important since each method has its own advantages and disadvantages (Dubovik, 2004). In this study, we used OE as the inversion method (Rodgers, 2000) since it has several advantages over other methods for OMIlike measurements, as discussed in Sect. 4. The atmospheric inverse problem often suffers from both insufficient information content of the measurements and imperfect measurement accuracy. Bayesian statistics provides mapping methods from the measurement probability density function (pdf) into state space with prior knowledge. Based on Bayes' theorem, the OE technique employs additional constraints from external sources (a priori) to complement the insufficient information content of the measurements. For the nonlinear inversion case, by considering the maximum a posteriori approach, the general form of the Bayesian solution can be expressed as Eq. (1) where measurement and a priori errors are assumed to be Gaussian (Rodgers, 2000):

$$
\begin{aligned}
-2 \ln P(\boldsymbol{x} \mid \boldsymbol{y}) & =[\boldsymbol{y}-\mathbf{K} \boldsymbol{x}]^{T} \mathbf{S}_{\epsilon}^{-1}[\boldsymbol{y}-\mathbf{K} \boldsymbol{x}] \\
& +\left[\boldsymbol{x}-\boldsymbol{x}_{\mathrm{a}}\right]^{T} \mathbf{S}_{\mathrm{a}}^{-1}\left[\boldsymbol{x}-\boldsymbol{x}_{\mathrm{a}}\right]+c,
\end{aligned}
$$

where $\boldsymbol{x}$ is the state vector and $\boldsymbol{y}$ the measurement vector, $\mathbf{K}$ is the weighting function matrix, $\mathbf{S}_{\epsilon}$ is the measurement error covariance matrix, $\boldsymbol{x}_{\mathrm{a}}$ is the a priori mean state, and $\mathbf{S}_{\mathrm{a}}$ is the a priori covariance matrix. The formulation finds the optimized solution that minimizes the cost function $(\chi)$ :

$\chi^{2}=\left\|\mathbf{S}_{\epsilon}^{-\frac{1}{2}}(\boldsymbol{y}-\mathbf{K} \boldsymbol{x})\right\|_{2}^{2}+\left\|\mathbf{S}_{\mathrm{a}}^{-\frac{1}{2}}\left(\boldsymbol{x}-\boldsymbol{x}_{\mathbf{a}}\right)\right\|_{2}^{2}$.

Detailed derivations and implications are described in previous studies (Rodgers, 2000; Wurl et al., 2010; Govaerts et al., 2010). As described above, the OMI near-UV algorithm uses radiance $\left(I_{388}\right)$ and spectral contrast $\left(I_{354} / I_{388}\right)$ for the measurement vector, where $I_{354}$ and $I_{388}$ are the normalized radiances at 354 and $388 \mathrm{~nm}$, respectively. The state vector in this study is the AOT at $388 \mathrm{~nm}\left(\tau_{388}\right)$ and the imaginary refractive index at $388 \mathrm{~nm}\left(n_{\mathrm{i}, 388}\right)$. Then, the weighting function matrix can be expressed as follows:

$\mathbf{K}=\left[\begin{array}{cc}\frac{\partial I_{388}}{\partial \tau_{388}} & \frac{\partial I_{388}}{\partial n_{\mathrm{i}, 388}} \\ \frac{\partial}{\partial \tau_{388}}\left(\frac{I_{354}}{I_{388}}\right) & \frac{\partial}{\partial n_{\mathrm{i}, 388}}\left(\frac{I_{354}}{I_{388}}\right)\end{array}\right]$,

where the weighting function of the spectral contrast can be obtained from the following derivative:

$\frac{\partial}{\partial x}\left(\frac{I_{354}}{I_{388}}\right)=\frac{\frac{\partial I_{354}}{\partial x} I_{388}-I_{354} \frac{\partial I_{388}}{\partial x}}{\left(I_{388}\right)^{2}}$.
In typical inversion methods, including OE, estimation of the reliable measurement error covariance matrix is important to determine the likelihood of the solution (Govaerts et al., 2010). The measurement error includes radiometric noise error and calibration accuracy. The absolute bidirectional scattering distribution function (BSDF) radiometric accuracy of the OMI instrument is reported to be about $4 \%$ for $2 \sigma$ and the random noise error is provided in the level $1 \mathrm{~b}$ product (Dobber et al., 2006). However, the reported BSDF uncertainty includes the errors in the calibration method and it represents the whole wavelength domain. Thus, actual BSDF uncertainty at 354 and $388 \mathrm{~nm}$ would be less than $2 \%$ (Jaross, 2015). In our experience, $2 \%$ of BSDF uncertainty leads to overestimates of the error and it is still challenging to evaluate. According to multiple retrieval tests, the BSDF uncertainty was assumed to be $1 \%$ in this study. The radiometric error covariance at each wavelength was calculated from the square root of the sum of squared radiometric uncertainty and calibration accuracy. The error covariance matrix can be written as

$\mathbf{S}_{\epsilon}=\left[\begin{array}{cc}\sigma\left(\epsilon_{388}\right)^{2} & \sigma\left(\epsilon_{388}, \epsilon_{354 / 388}\right)^{2} \\ \sigma\left(\epsilon_{388}, \epsilon_{354 / 388}\right)^{2} & \sigma\left(\epsilon_{354 / 388}\right)^{2}\end{array}\right]$,

where $\epsilon_{\lambda}$ is the total error of the measured radiance at wavelength $\lambda, \epsilon_{354 / 388}$ is the error of $I_{354} / I_{388}$, which is described later in this section; and $\sigma\left(\epsilon_{388}, \epsilon_{354 / 388}\right)^{2}$ is the covariance between the total measurement errors of $I_{388}$ and $I_{354} / I_{388}$.

The $\epsilon_{\lambda}$ typically includes both random and systematic components and its covariance can be expressed as follows:

$\sigma\left(\epsilon_{\lambda}\right)^{2}=\sigma\left(\epsilon_{\mathrm{r}, \lambda}\right)^{2}+\sigma\left(\epsilon_{\mathrm{s}, \lambda}\right)^{2}$,

where $\epsilon_{\mathrm{r}, \lambda}$ and $\epsilon_{\mathrm{s}, \lambda}$ are the random and systematic components of radiometric error at $\lambda$; and $\sigma\left(\epsilon_{\mathrm{r}, \lambda}\right)^{2}$ and $\sigma\left(\epsilon_{\mathrm{s}, \lambda}\right)^{2}$ are their covariance values, respectively. The $\epsilon_{354 / 388}$ can be approximated as follows:

$$
\begin{aligned}
\epsilon_{354 / 388} & \cong \frac{I_{354}}{I_{388}}-\frac{I_{354}+\epsilon_{354}}{I_{388}+\epsilon_{388}} \cong \frac{I_{354}}{I_{388}}\left(\frac{\epsilon_{354}}{I_{354}}-\frac{\epsilon_{388}}{I_{388}}\right) \\
& \cong \frac{I_{354}}{I_{388}}\left(\frac{\epsilon_{\mathrm{s}, 354}}{I_{354}}-\frac{\epsilon_{\mathrm{s}, 388}}{I_{388}}+\frac{\epsilon_{\mathrm{r}, 354}}{I_{354}}-\frac{\epsilon_{\mathrm{r}, 388}}{I_{388}}\right) .
\end{aligned}
$$

When the systematic components of the measurement errors of radiances at 354 and $388 \mathrm{~nm}$ are positively correlated and their values are similar, part of the systematic uncertainties can be reduced by the $\frac{\epsilon_{\mathrm{s}, 354}}{I_{354}}-\frac{\epsilon_{\mathrm{s}, 388}}{I_{388}}$ term. However, assessment of the systematic error of OMI measurements at each pixel is still challenging despite this partial reduction of systematic errors by using $I_{354} / I_{388}$. In this study, the BSDF calibration uncertainties of $I_{354}$ and $I_{388}$ at a pixel are assumed to be systematic and similar, while the radiometric noise values of $I_{354}$ and $I_{388}$ are assumed to be random and independent. Then, the systematic measurement error of $\epsilon_{354 / 388}$ can be regarded as negligible and the covariance of $\epsilon_{354 / 388}$ in 
Table 4. Diagonal and off-diagonal elements of the measurement error covariance matrices using two different measurement matrices.

\begin{tabular}{lll}
\hline Measurement matrix & {$\left[I_{354} I_{388}\right]^{\mathrm{T}}$} & {$\left[I_{354} \frac{I_{354}}{I_{388}}\right]^{\mathrm{T}}$} \\
\hline First diagonal term & $\sigma\left(\epsilon_{354}\right)^{2}$ & $\sigma\left(\epsilon_{388}\right)^{2}$ \\
Second diagonal term & $\sigma\left(\epsilon_{388}\right)^{2}$ & $\left(\frac{I_{354}}{I_{388}}\right)^{2}\left\{\left(\frac{\epsilon_{\mathrm{r}, 354}}{I_{354}}\right)^{2}+\left(\frac{\epsilon_{\mathrm{r}, 388}}{I_{388}}\right)^{2}\right\}$ \\
Off-diagonal term & $\sigma\left(\epsilon_{354}, \epsilon_{388}\right)^{2}$ & 0 \\
\hline
\end{tabular}

Eq. (7) can be approximated as follows:

$\sigma\left(\epsilon_{354 / 388} \cong \frac{I_{354}}{I_{388}} \sqrt{\left(\frac{\epsilon_{\mathrm{r}, 354}}{I_{354}}\right)^{2}+\left(\frac{\epsilon_{\mathrm{r}, 388}}{I_{388}}\right)^{2}}\right.$

The $\sigma\left(\epsilon_{388}, \epsilon_{354 / 388}\right)^{2}$ can be obtained as follows:

$\sigma\left(\epsilon_{388}, \epsilon_{354 / 388}\right)^{2}=\frac{1}{n-1} \sum_{i=1}^{n} \epsilon_{388}^{i} \epsilon_{354 / 388}^{i}$

where $\epsilon_{388}^{i}$ and $\epsilon_{354 / 388}^{i}$ are the uncertainties in the $i$ th measurement of $I_{388}$ and $I_{354} / I_{388}$ for a sample of size $n$, respectively. Under the same assumptions used in Eqs. (7) and (8), $\epsilon_{354 / 388}^{i}$ has only random and independent components, and so $\sigma\left(\epsilon_{388}, \epsilon_{354 / 388}\right)$ can be regarded as negligible. The diagonal and off-diagonal elements of the measurement error covariance matrices using two different measurement matrices are compared in Table 4.

\subsection{Error characterization}

Retrieved products with estimated and/or characterized error are valuable for any application. Various error sources can be categorized as shown in the following equation by linearizing the forward model with respect to associated parameters (Eyre, 1987; Rodgers, 1990, 2000):

$$
\begin{aligned}
\hat{\boldsymbol{x}}-\boldsymbol{x} & =\left(\mathbf{A}-\mathbf{I}_{n}\right)\left(\boldsymbol{x}-\boldsymbol{x}_{\mathrm{a}}\right)+\mathbf{G}_{y} \mathbf{K}_{b}(\boldsymbol{b}-\hat{\boldsymbol{b}}) \\
& +\mathbf{G}_{y} \Delta f\left(\boldsymbol{x}, \boldsymbol{b}, \boldsymbol{b}^{\prime}\right)+\mathbf{G}_{y} \epsilon,
\end{aligned}
$$

where $\hat{\boldsymbol{x}}$ and $\boldsymbol{x}$ are the retrieval and true states, respectively; $\mathbf{A}$ is the averaging kernel matrix; $\mathbf{I}_{n}$ is the identity matrix; $\boldsymbol{x}_{\mathrm{a}}$ is the a priori state vector; $\mathbf{G}_{y}$ is the contribution function matrix; $\mathbf{K}_{b}$ is the weighting function matrix of forward model parameters $(\boldsymbol{b}) ; \hat{\boldsymbol{b}}$ is the guessed forward model parameter; $\Delta f$ is the error in the forward model relative to the real physics; and $\epsilon$ is the measurement error. The first and last term on the right-hand side (RHS) of Eq. (10) is the smoothing error and retrieval noise, respectively. Their covariance matrices can be calculated from

$\mathbf{S}_{\mathrm{s}}=\left(\mathbf{A}-\mathbf{I}_{n}\right) \mathbf{S}_{\mathrm{E}}\left(\mathbf{A}-\mathbf{I}_{n}\right)^{\mathrm{T}}$

$\mathbf{S}_{\mathrm{n}}=\mathbf{G}_{y} \mathbf{S}_{\epsilon} \mathbf{G}_{y}^{\mathrm{T}}$,

where $\mathbf{S}_{\mathrm{s}}$ is the smoothing error covariance matrix, $\mathbf{S}_{\mathrm{E}}$ is the covariance of the ensemble of states about the mean state, and $\mathbf{S}_{\mathrm{n}}$ is the covariance matrix of the retrieval noise. We have assumed that the climatological value is a good representation of the real ensemble of the state about the mean state, and so the covariance matrix of the a priori state was employed as the $\mathbf{S}_{\mathrm{E}}$ in this study. Each $\mathbf{S}_{\mathrm{s}}$ and $\mathbf{S}_{\mathrm{n}}$ has two diagonal elements that represent the variances of the smoothing error and retrieval noise for two retrievals, AOT and SSA. The smoothing error $\left(\varepsilon_{\mathrm{sm}}\right)$ and retrieval noise $\left(\varepsilon_{\mathrm{n}}\right)$ of AOT and SSA were defined as the square root of the corresponding diagonal elements of $\mathbf{S}_{\mathrm{s}}$ and $\mathbf{S}_{\mathrm{n}}$, respectively. The square root of the sum of squared $\varepsilon_{\mathrm{sm}}$ and $\varepsilon_{\mathrm{n}}$ of AOT and SSA are defined in this study as the solution errors $\left(\varepsilon_{\text {sol }}\right)$ of AOT and SSA, respectively.

The second term on the RHS of Eq. (10) is the forward model parameter error, and its covariance matrix can be calculated as follows:

$\mathbf{S}_{\mathrm{f}}=\mathbf{G}_{y} \mathbf{K}_{b} \mathbf{S}_{b} \mathbf{K}_{b}^{\mathrm{T}} \mathbf{G}_{y}^{\mathrm{T}}$,

where $\mathbf{S}_{\mathrm{f}}$ is the covariance matrix of the forward model parameter error, and $\mathbf{S}_{b}$ is the error covariance matrix of the forward model parameter, $\boldsymbol{b}$. The forward model parameters of the near-UV method include the aerosol microphysical model parameters, aerosol vertical distribution, meteorological profile (pressure and temperature), and surface properties. These forward model parameters contain both random and systematic components with different scales of spatial and temporal variation. Furthermore, each forward model parameter has a different uncertainty that is difficult to evaluate. In this study, $\mathbf{S}_{\mathrm{f}}$ was analyzed separately with respect to each forward model parameter as suggested by Rodgers (2000). The forward model parameter error $\left(\varepsilon_{\mathrm{f}}\right)$ of AOT and SSA were obtained from the square root of the corresponding diagonal elements of each $\mathbf{S}_{\mathrm{f}}$.

The third term on the RHS in Eq. (10) is the forward model error that is caused by discrepancies between known and real physics. To simulate the earth-reflected radiance, VLIDORT (linearized pseudo-spherical vector discrete ordinate radiative transfer code, version 2.6) was used. This code is based on one of the most accurate radiative transfer solutions for a one-dimensional atmosphere (Spurr, 2006). Linearization of state vectors and forward model parameters are described in prior papers (Spurr et al., 2012; Spurr and Christi, 2014). Although the simulated radiances are expected to be accurate, the forward model error depends on factors including the number of streams, layers, and Legendre coefficients 

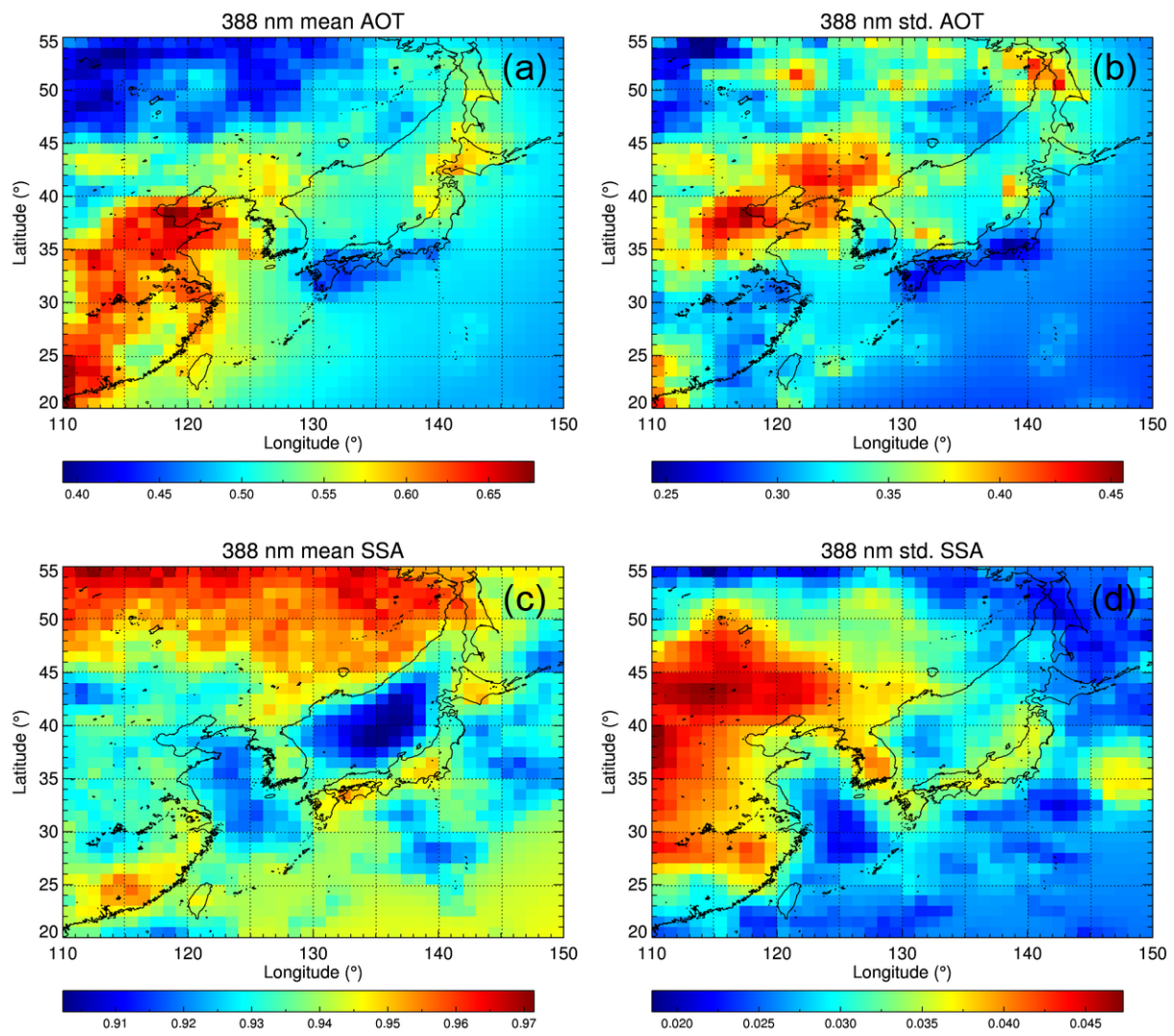

Figure 2. (a) Mean and (b) standard deviation of $388 \mathrm{~nm}$ AOT from the OMAERUV product in spring (March to May) 2005-2014. Panels (c) and (d) show the average and standard deviation of SSA, respectively, during the same period.

for the aerosol phase functions. To reduce the numerical errors that can arise from an insufficient number of coefficients, 3 Stokes parameters, 75 layers, 16 streams, and up to 500 Legendre coefficients for the aerosol phase matrix were used for the radiance simulations. However, it is still a challenge to evaluate other possible sources of forward model error such as Raman scattering and the three-dimensional effect of the atmosphere for retrieval. Such issues are beyond the scope of this study, and thus only smoothing error, retrieval noise, and the forward model parameter error are evaluated here.

\subsection{A priori characterization}

Using reliable a priori information is important in the $\mathrm{OE}$ method since the final solutions are determined between the a priori state and the inversion space of a measurement. There are several sources of a priori information including climatological data, reliable measurements from more accurate instruments, and calculations from models based on theoretical or empirical statistics (Govaerts et al., 2010; Wurl et al., 2010; Rodgers, 2000). Appropriate sources of a priori depend on the characteristics of the state vector and the accuracy of the a priori database. When the a priori state has a systematic bias away from the true state, this bias propagates to the re- trieval products. In this study, 10 years (from 2005 to 2014) of OMAERUV $388 \mathrm{~nm}$ AOT and SSA in spring (from March to May) were used for the a priori data. Figure 2 shows the collected climatological data of the $388 \mathrm{~nm}$ AOT and SSA in east Asia used in this study. To avoid biases due to cloud contamination in the OMI products, averaged values and standard deviations $(\sigma)$ with more than 70 data points were used.

\section{Results}

The dust event on 28 April 2012 has been selected to compare the aerosol optical properties from the operational product with the OE-based retrievals in this study. Figure 3 shows the true color image on that day from the Moderate Resolution Imaging Spectroradiometer (MODIS) Aqua and the UV aerosol index from OMI. To see the difference between the OE-based and operational algorithm in the same area, both methods were applied to measurements with an operational algorithm flag of 0 , to avoid cloud contamination and radiometric calibration uncertainties. Some of the points retrieved by the operational algorithm were rejected in the OE-based retrievals when the cost function cut-off was applied, as described in this section. 


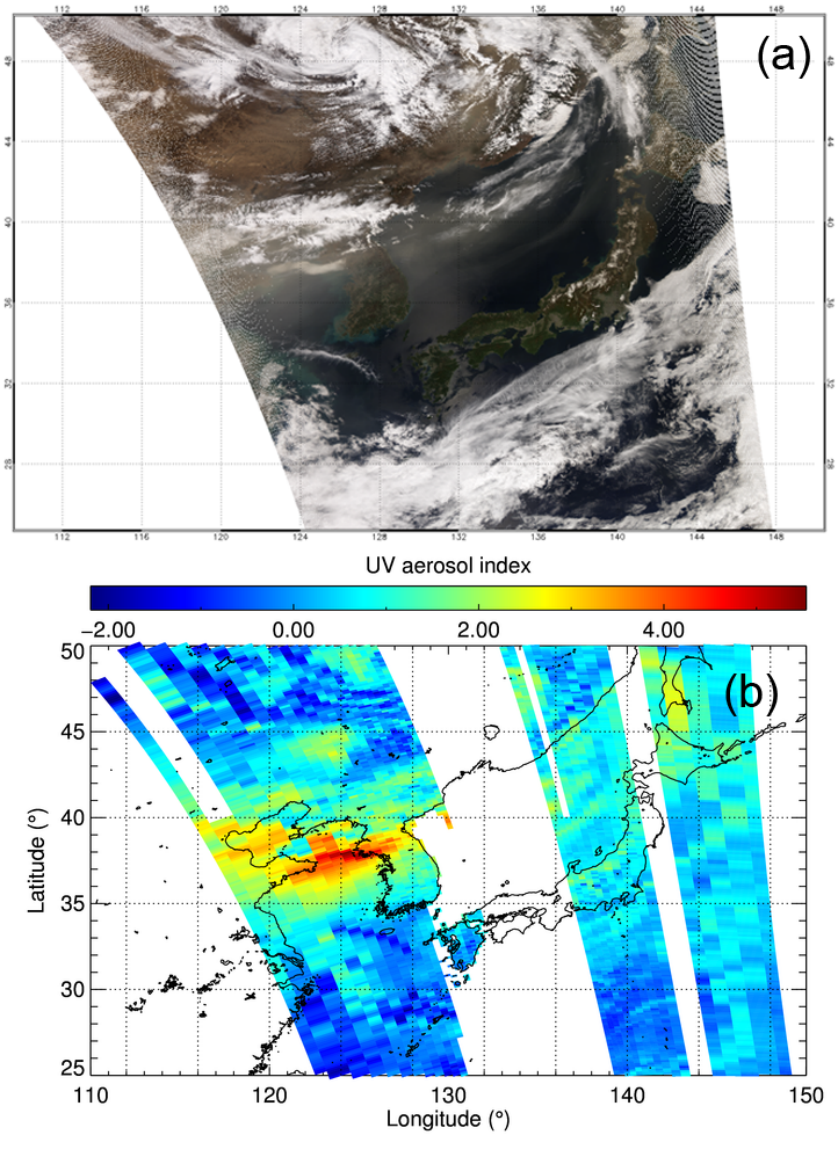

Figure 3. (a) MODIS Aqua true color image and (b) UV aerosol index from the OMI product in northeast Asia on 28 April 2012.

The AOT and SSA at $388 \mathrm{~nm}$ from the operational and OE-based products are compared in Fig. 4 . The $\varepsilon_{\text {sol }}$ of the retrieved AOT and SSA at $388 \mathrm{~nm}$, degree of freedom, and $\chi$ are shown in Fig. 5. The OE-based and operational AOT at $388 \mathrm{~nm}$ are similar, as shown in Fig. 4a and b. Both products seem to be affected by snow- and cloud-contaminated pixels around Seoul in South Korea $\left(37^{\circ} \mathrm{N}, 126^{\circ} \mathrm{E}\right)$, Tianjin in China $\left(39^{\circ} \mathrm{N}, 116^{\circ} \mathrm{E}\right)$, and Nagano in Japan $\left(36^{\circ} \mathrm{N}\right.$, $138^{\circ}$ E). In Fig. $5 \mathrm{a}$, the $\varepsilon_{\text {sol }}$ of retrieved AOT at $388 \mathrm{~nm}$ has relatively high values compared with the AOT level at large viewing zenith angles. Noticeable discrepancies of SSA at $388 \mathrm{~nm}$ from the operational and OE-based products are evident in some of the areas as shown in Fig. $4 \mathrm{c}$ and d. The operational algorithm performed single-channel retrieval around east Mongolia $\left(47^{\circ} \mathrm{N}, 115^{\circ} \mathrm{E}\right)$, while the OE-based algorithm performed two-channel retrieval for all cases. Since this area has a low level of AOT, the information content of aerosol absorption property is insufficient, resulting in the low degrees of freedom shown in Figs. $4 \mathrm{~b}$ and $5 \mathrm{c}$. Thus the OE-based SSA in this area (Fig. 4d) seems noisy and the $\varepsilon_{\text {sol }}$ of SSA appears high. Similar results for the behavior of SSA are apparent around central Japan $\left(38^{\circ} \mathrm{N}, 138^{\circ} \mathrm{E}\right)$.
Thus, SSA values with high AOT and low $\varepsilon_{\text {sol }}$ are recommended for the analysis, similar to the retrieval conditions for AERONET inversion products (Dubovik and King, 2000). Additional information provided on retrievals at each pixel in Fig. 5 is expected to be valuable for relevant studies including trace gas retrieval and data assimilation.

Figure 6 shows the results of validation of operational and OE-based AOT retrievals at $388 \mathrm{~nm}$. As shown in Fig. 6a and $b$, the OE-based inversion method showed a higher correlation coefficient $(r=0.82)$ and slightly improved slope $(0.83)$ and offset $(0.16)$ values than the operational algorithm $(r=0.71$, slope $=0.71$, and offset $=0.2)$. The Fisher's $z$ value between the correlation coefficients (Fisher, 1921) was 3.04 corresponding to a two-tailed $p$ value of 0.0024 . The Student's $t$ value for the difference between the two slopes is 2.10 with 512 degrees of freedom with the twotailed $p$ value of 0.04 . The statistical values show that difference between the two correlation coefficients and slopes are significant ( $p$ value $<0.05$ ). The $Q$ values (percentage of AOT retrievals falling within an uncertainty envelope of $\pm 30 \%$ or 0.1 ) of the OE-based retrievals and operational algorithm were similar $(63.0 \%)$. When a measured radiance is affected by parameters that the theoretical radiative transfer model does not consider (e.g., sub-pixel cloud contamination), the $\chi$ of the retrieval typically has a high value. In this study, retrievals with $\chi$ larger than a certain value (i.e., 2.0 in this study) have been rejected. This limitation on retrievals imposed by the $\chi$ reduced the number of retrievals with abnormally high biases, which might be associated with sub-pixel cloud contamination, in the operational algorithm in Fig. 6a.

The SSA values at $388 \mathrm{~nm}$ from OMI operational products and OE-based inversion products were compared with those at 388 and $440 \mathrm{~nm}$ from AERONET inversion products as shown in Fig. 7. The retrieved SSA at $388 \mathrm{~nm}$ from the operational algorithm showed comparable or higher values of $Q_{0.03}(59.2 \%)$ and $Q_{0.05}(85.1 \%)$ with those from the OE-based algorithm $\left(Q_{0.03}=53.5 \%, Q_{0.05}=86.0 \%\right)$ when compared with the AERONET SSA at $440 \mathrm{~nm}$. (The $Q_{0.03}$ and $Q_{0.05}$ represent the percentage of SSA retrievals falling within an uncertainty envelope of \pm 0.03 and \pm 0.05 , respectively.) The retrieved $388 \mathrm{~nm}$ SSA from both the operational and OE-based algorithms showed similar correlation with the AERONET $(r=0.27$ and 0.26 for operational and OE-based algorithms, respectively. Fisher's $z$ value is 0.1 with two-tailed $p$ value of 0.92 ). The retrieved SSA at $388 \mathrm{~nm}$ from the operational and OE-based algorithms showed slightly higher correlation with the converted $388 \mathrm{~nm}$ SSA from AERONET ( $r=0.34$ and 0.33 for the operational and OE-based algorithm, respectively) than with the $440 \mathrm{~nm}$ SSA from AERONET. However, the significances of the differences in $r$ between converted and unconverted SSA comparisons were low (Fisher's $z$-values were 0.71 and 0.67 with two-tailed $p$-values of 0.48 and 0.50 for the operational algorithm and OE-based algorithm, respectively). 

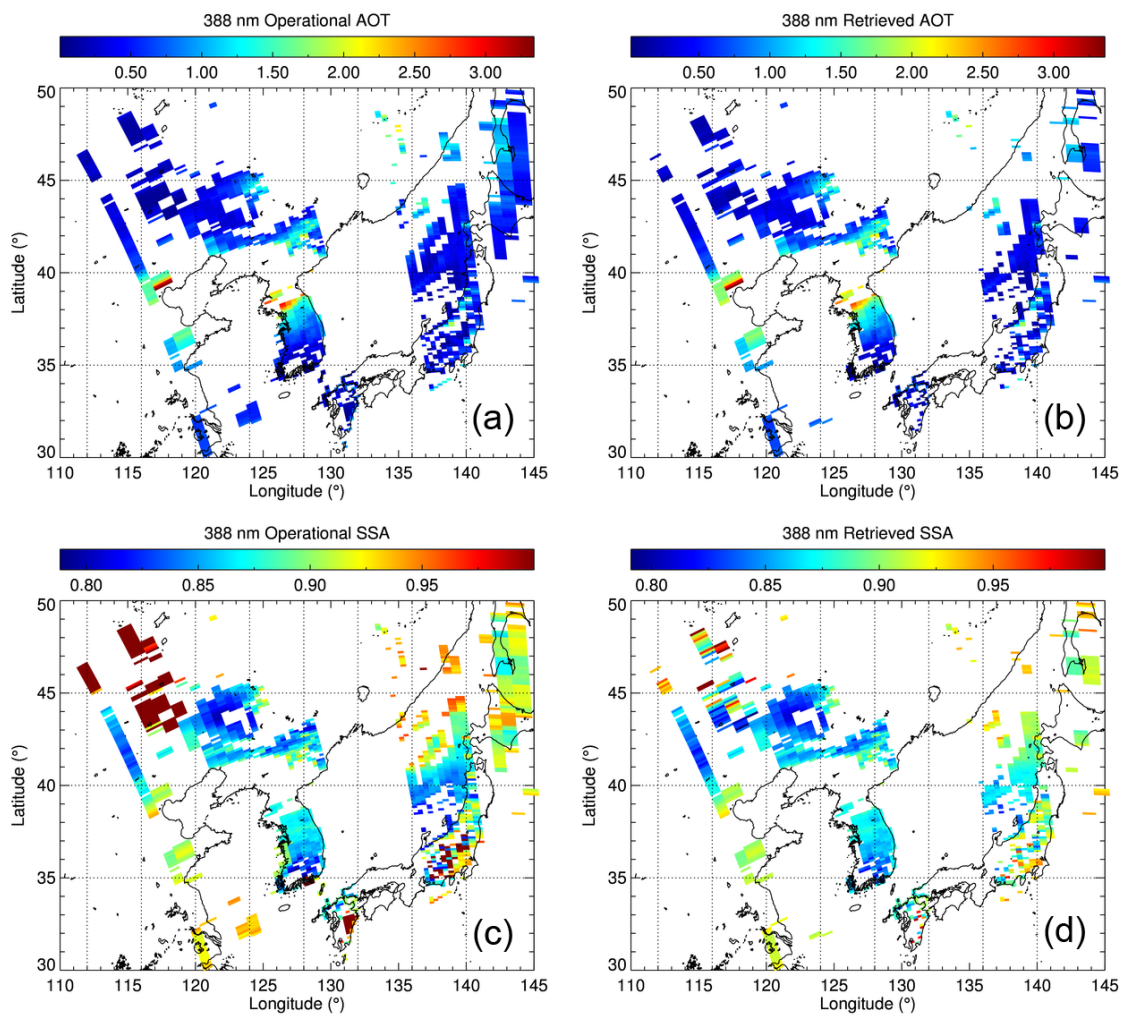

Figure 4. (a) OMI operational AOT, (b) OE-based AOT, (c) operational SSA, and (d) OE-based SSA on 28 April 2012 at $388 \mathrm{~nm}$.
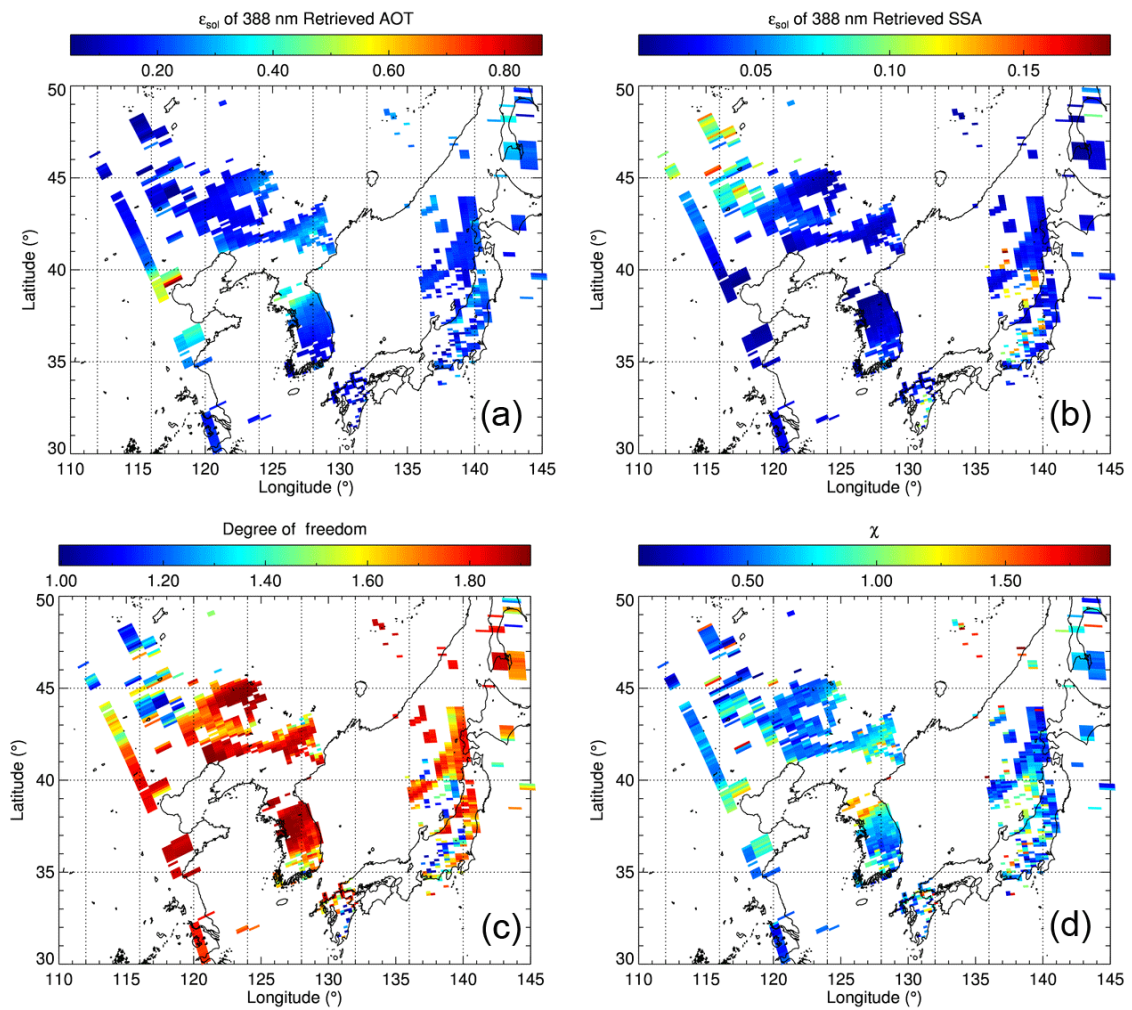

Figure 5. Estimated solution error of (a) OE-based $388 \mathrm{~nm}$ AOT and (b) SSA. Panels (c) and (d) show the degrees of freedom and cost function of the retrieval, respectively. 

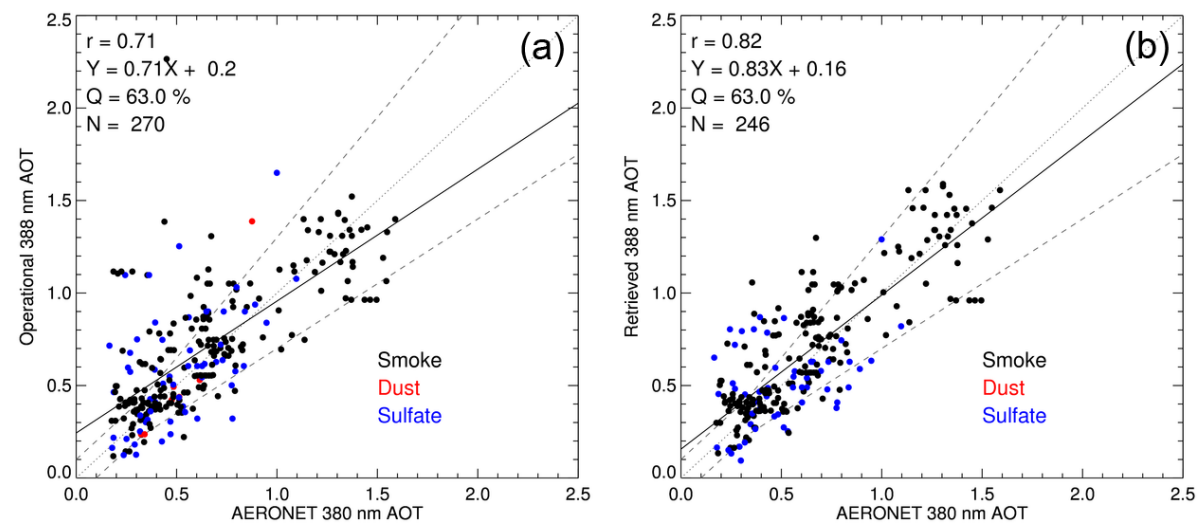

Figure 6. Validation of $388 \mathrm{~nm}$ AOT against AERONET data from (a) operational products and (b) the OE-based algorithm during the DRAGON-NE Asia 2012 campaign.
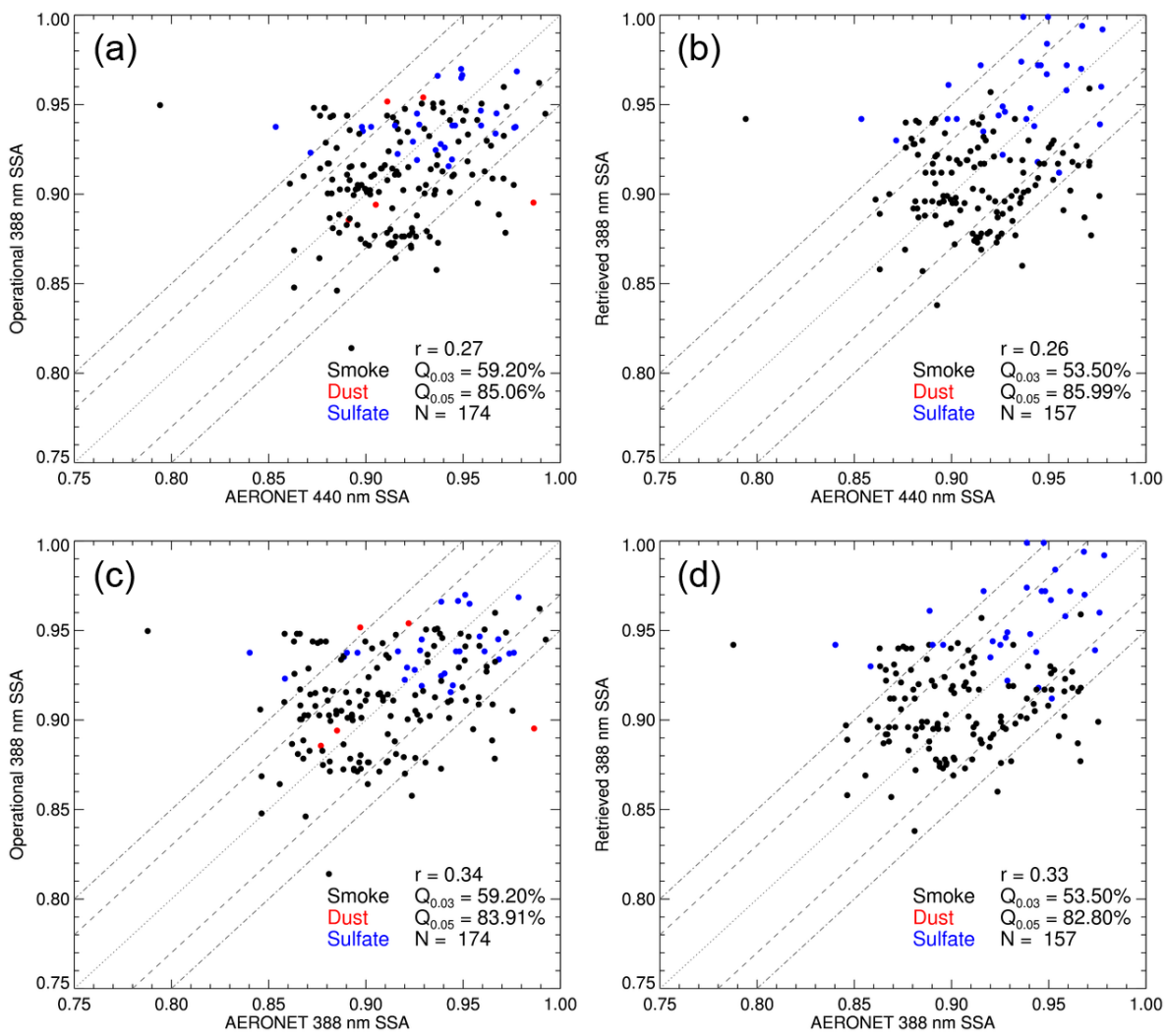

Figure 7. Comparison of the $440 \mathrm{~nm}$ SSA from AERONET and $388 \mathrm{~nm}$ SSA from (a) the operational products and (b) the OE-based algorithm, during the DRAGON-NE Asia 2012 campaign. Panels (c) and (d) compare converted $388 \mathrm{~nm}$ SSA from AERONET with that from (c) the operational products and (d) the OE-based algorithm.

The retrieved SSA at $388 \mathrm{~nm}$ from the operational algorithm also showed comparable or higher values of $Q_{0.03}(59.2 \%)$ and $Q_{0.05}(83.9 \%)$ than those of the OE-based algorithm $\left(Q_{0.03}=53.5 \%, Q_{0.05}=82.8 \%\right)$ when compared with converted SSA at $388 \mathrm{~nm}$ from AERONET.

The estimated retrieval uncertainties of the AOT at $388 \mathrm{~nm}$ from the operational algorithm $\left(\varepsilon_{\mathrm{omi}}, \pm 30 \%\right.$ or 0.1$)$ and estimated $\varepsilon_{\text {sol }}$ were plotted against the biases relative to AERONET measurements as shown in Fig. 8. The percentages of AOT retrieval biases from AERONET falling within the estimated retrieval errors of operational $\left(Q_{\text {omi }}\right)$ and OEbased method $\left(Q_{\text {sol }}\right)$ were $64.8 \%$ and $65.9 \%$, respectively. The $Q_{\text {sol }}$ was higher than $Q_{\text {omi }}$ despite the lower mean value of $\varepsilon_{\text {sol }}(0.20)$ than $\varepsilon_{\text {omi }}(0.21)$. The error bars and black 

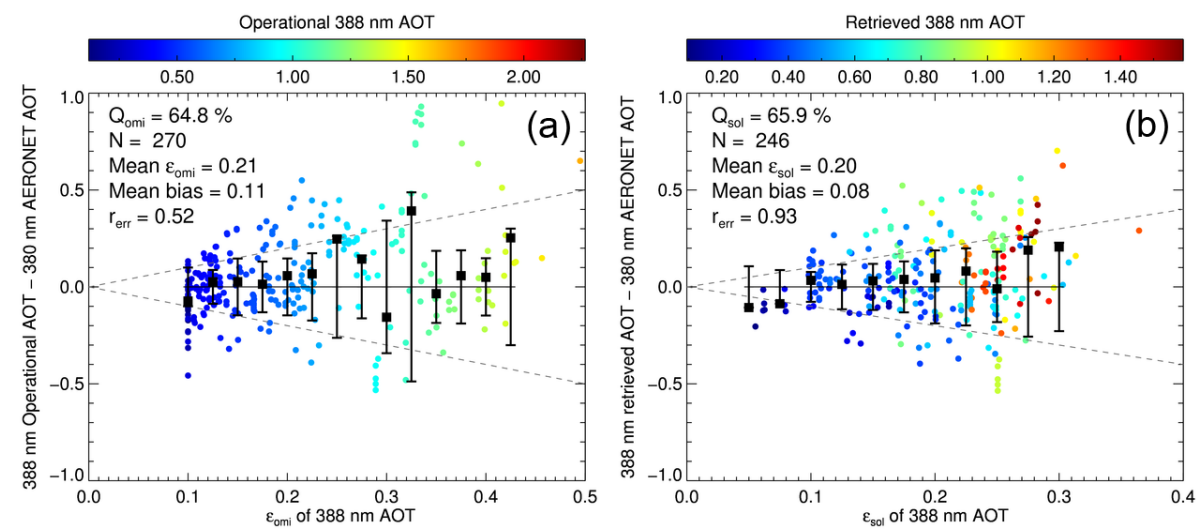

Figure 8. Comparison between estimated uncertainties of the $388 \mathrm{~nm}$ AOT ( $x$ axis) and biases of retrieved AOT from AERONET measurements ( $y$ axis). The panels (a) and (b) are based on the operational and OE-based retrieval/error-estimation algorithm, respectively.

Table 5. Error sources and their assumed magnitudes in the OMI ATBD (Algorithm Theoretical Basis Documents) and this study.

\begin{tabular}{|c|c|c|}
\hline Error source & $\begin{array}{l}\text { Error perturbation } \\
\text { (OMI ATBD) }\end{array}$ & $\begin{array}{l}\text { Assumed value of } \sigma \text { for each } \\
\text { error source in this study }\end{array}$ \\
\hline Cloud contamination & $5 \%$ cloud contamination & $\mathrm{N} / \mathrm{A}^{\mathrm{b}}$ \\
\hline Surface reflectivity & 0.01 error in surface reflectivity & 0.01 for both wavelengths \\
\hline $\begin{array}{l}\text { Radiometric } \\
\text { uncertainty }\end{array}$ & $\begin{array}{l}\text { SNR less than } 1 \% \\
\text { Radiometric offset additive error of } 1 \% \\
\text { Radiometric scale factor multiplicative error of } 1 \%\end{array}$ & $\begin{array}{l}1 \% \text { of BSDF calibration uncertainty } \\
\text { (Dobber et al., 2006; Jaross, 2015) } \\
\text { Radiometric precision provided by Level 1b data }\end{array}$ \\
\hline $\begin{array}{l}\text { Size distribution } \\
\text { (mode radius) }\end{array}$ & $5 \%$ increase of mode radius & $\begin{array}{l}0.019 \text { for fine mode } \\
0.510 \text { for coarse mode }\end{array}$ \\
\hline $\begin{array}{l}\text { Size distribution } \\
\text { (width) }\end{array}$ & $5 \%$ increase of width & $\begin{array}{l}0.265 \text { for fine mode } \\
0.307 \text { for coarse mode }\end{array}$ \\
\hline Fine-mode fraction & N/A & $0.0015^{\mathrm{a}}$ \\
\hline Refractive index & $\begin{array}{l}\text { Increase with } 0.05 \text { for } n_{\mathrm{r}} \\
\text { Increase with } 0.01 \text { for } n_{\mathrm{i}}\end{array}$ & $\begin{array}{l}0.053 \text { for } n_{\mathrm{r}} \text { (for all wavelengths and size modes) } \\
0.0047 \text { for } 354 \mathrm{~nm} n_{\mathrm{i}}^{\mathrm{a}}\end{array}$ \\
\hline $\begin{array}{l}\text { Aerosol vertical } \\
\text { profile }\end{array}$ & Change of $1 \mathrm{~km}$ peak height & $\begin{array}{l}\text { Change of } 2 \mathrm{~km} \text { peak height } \\
\text { Change of } 1 \mathrm{~km} \text { half width }\end{array}$ \\
\hline Particle shape & N/A & N/A \\
\hline
\end{tabular}

squares in Fig. 8 represent the moving $\sigma$ and average value of the retrieval biases from AERONET as a function of estimated error, respectively. As shown in Fig. $8 \mathrm{~b}, \varepsilon_{\text {sol }}$ explained the moving $\sigma$ of the actual biases $(r=0.93)$ better than $\varepsilon_{\text {omi }}$ in Fig. $8 \mathrm{a}(r=0.52)$. Fisher's $z$ value between the correlation coefficients was 2.33 with a two-tailed $p$ value of 0.02 . The systematic biases of $\varepsilon_{\text {sol }}$ and $\varepsilon_{\text {omi }}$ (represented by the moving average of each error estimates) are typically related to other error sources, including forward model parameters and subpixel cloud contaminations. Since the $\varepsilon_{\text {sol }}$ of retrieved AOT considers the theoretical sensitivity of the retrieval biases to associated parameters, it explained the retrieval uncertainties better than the $\varepsilon_{\text {omi }}$, which only considers the retrieved AOT values.

Table 5 shows the suggested error sources and their magnitudes from the OMI ATBD (Algorithm Theoretical Basis Documents) (Torres et al., 2002b) and the values employed in this study. Although the current OMI cloud masking method is based on long-term TOMS heritage, there may still be ground pixels contaminated by sub-pixel clouds. As the TOA reflectance is greatly increased by even a small amount of cloud, cloud contamination can cause large positive biases in the AOT retrieval. Previous studies estimated the AOT retrieval errors due to $5 \%$ cloud contamination to be of the 
order of 0.1 to 0.2 (Torres et al., 1998, 2002b). They also reported an even higher error in the single scattering albedo (0 to 0.15 ), especially for strongly absorbing aerosols. However, estimation of sub-pixel cloud contamination is difficult because of the large spatiotemporal variability of clouds and the relatively large ground pixel size of OMI. Thus the further error analysis of cloud contamination error budget from Torres et al. (2002b) was not performed in this study. Typical uncertainties of the 354 and $388 \mathrm{~nm}$ surface reflectances were assumed to be 0.01 for both land and ocean. The BSDF accuracy was assumed to be $1 \%$ (Dobber et al., 2006; Jaross, 2015), and the radiometric precision was obtained from OMI Level $1 \mathrm{~b}$ data. To analyze the uncertainty associated with the aerosol size information and refractive index, $\sigma$ values of the size parameter and $n_{\mathrm{r}}$ at $440 \mathrm{~nm}$ were taken from AERONET inversion products during the campaign period. To analyze the assumed $n_{\mathrm{i}}$ at $354 \mathrm{~nm}$, the $\mathbf{S}_{b}$ was also obtained from AERONET statistics during the campaign period. Aerosol vertical distribution is important as it affects aerosol retrieval using near-UV and blue channels, particularly for absorbing aerosols (Torres et al., 1998; de Graaf et al., 2005; Torres et al., 2013). However, accuracy assessments of the aerosol height information used are still challenging. Typical uncertainties of the assumed aerosol layer peak height and half width were assumed to be 2 and $1 \mathrm{~km}$, respectively, in this study. In the OE-based near-UV aerosol retrieval algorithm, all aerosols are assumed to be spherical and the optical properties are calculated from aerosol microphysical properties using the Mie solution. However, nonsphericity may cause significant uncertainties, especially for large particles (Mishchenko and Travis, 1994; Mishchenko et al., 1995, 1997, 2003; Dubovik et al., 2006), and aerosol morphology is quite complicated and requires further analysis for the near-UV region. This is out of the scope of this study and thus needs to be investigated in a future study. Therefore the uncertainties due to aerosol non-sphericity were not analyzed.

Figure 9 shows the average and $\sigma$ values of $\varepsilon_{\mathrm{f}}$ of the retrieved AOT and SSA that were sampled for the validation in Figs. $6 \mathrm{~b}$ and $7 \mathrm{~b}$, d. High values of $\varepsilon_{\mathrm{f}}$ for AOT appeared in $n_{\mathrm{i}}$ at $354 \mathrm{~nm}(0.34 \pm 0.25)$, surface reflectance at $388 \mathrm{~nm}(0.19 \pm 0.07)$, and the number fine-mode fraction (FMF) $(0.16 \pm 0.09)$. These values are higher or comparable with the mean $\varepsilon_{\text {sol }}$ of retrieved AOT at $388 \mathrm{~nm}(0.20)$. Thus, the accuracy of AOT retrievals depends not only on the radiometric accuracy and information content, but also on the aerosol models and ancillary data of the surface reflectance, of which the effect is already well known. The FMFs of the sulfate- (0.999596) and smoke-type aerosols (0.999795) are similar, while the FMF for dust-type aerosols is quite different $(0.995650)$. Considering that the estimated $\sigma$ value for FMF uncertainty in this study $(0.0015$, see Table 5$)$ is much lower than the difference between the FMFs of dust type and other aerosols $(\sim 0.004$, see Table 2$)$, the errors resulting from the selection of the wrong aerosol type can be
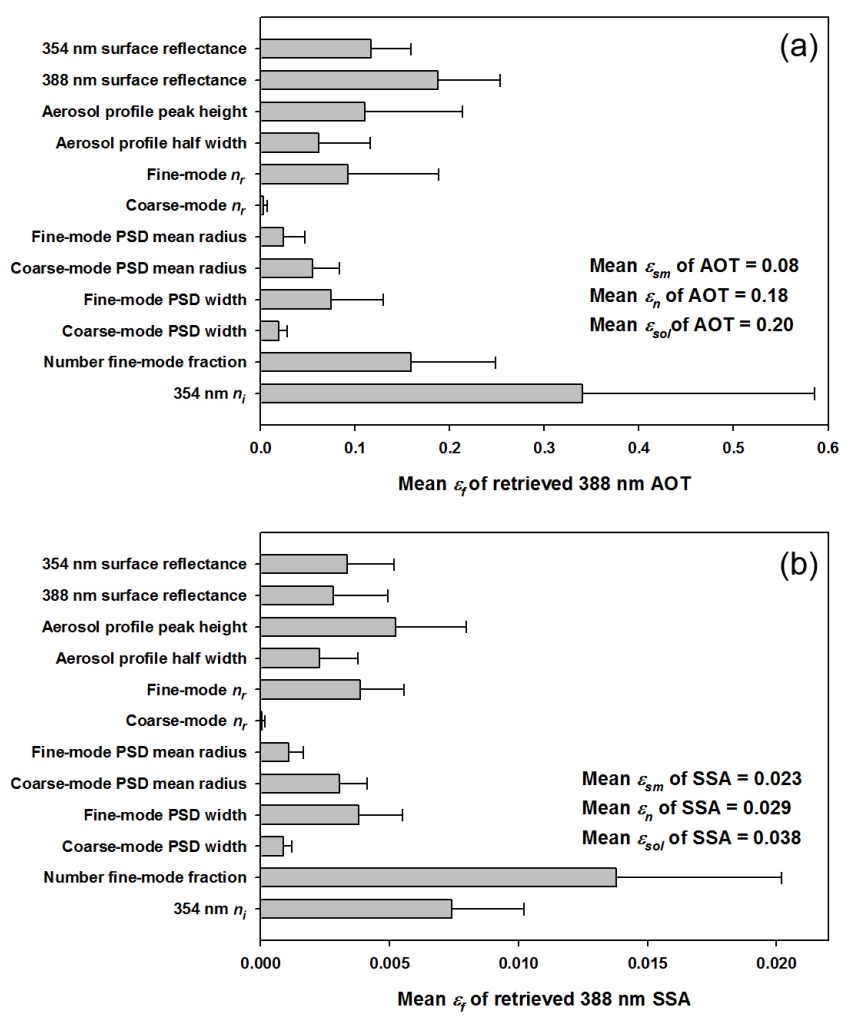

Figure 9. Average (gray bars) and standard deviation (black lines) of the forward model parameter errors of $388 \mathrm{~nm}$ (a) AOT and (b) SSA.

more significant. The estimated $\varepsilon_{\mathrm{f}}$ of the surface reflectance at $388 \mathrm{~nm}$ was higher than the previously suggested value (0.07-0.09 for AOT and <0.01 for SSA) in the OMI ATBD (Torres et al., 2002b). The $\varepsilon_{\mathrm{f}} \mathrm{s}$ of AOT with respect to the surface reflectance at $354 \mathrm{~nm}(0.12 \pm 0.04)$, peak height of the aerosol vertical distribution $(0.11 \pm 0.10)$, fine-mode $n_{\mathrm{r}}$ $(0.09 \pm 0.10)$, half width of the fine-mode PSD $(0.07 \pm 0.06)$, mean radius of the coarse-mode PSD $(0.06 \pm 0.03)$, and half width of the aerosol vertical distribution $(0.06 \pm 0.05)$ showed similar moderate sensitivity. Those for the mean radius of the fine-mode PSD $(0.02 \pm 0.02)$ and half width of the coarse mode PSD $(0.02 \pm 0.01)$ were smaller and that of the coarse-mode $n_{\mathrm{r}}(0.003 \pm 0.004)$ was found to be negligible.

Among $\varepsilon_{\mathrm{f}} \mathrm{s}$ of the SSA retrieval, the FMF error $(1.4 \times$ $10^{-2} \pm 6.4 \times 10^{-3}$ ) was the most important of the $\varepsilon_{\mathrm{f}} \mathrm{s}$ of the SSA retrieval. Errors in $n_{\mathrm{i}}$ at $354 \mathrm{~nm}\left(7.4 \times 10^{-3} \pm 2.8 \times\right.$ $10^{-3}$ ) and the peak height of the aerosol vertical distribution $\left(5.2 \times 10^{-3} \pm 2.8 \times 10^{-3}\right)$ were found to be the second most important. The $\varepsilon_{\mathrm{f}}$ of SSA with respect to the fine-mode $n_{\mathrm{r}}\left(3.9 \times 10^{-3} \pm 1.7 \times 10^{-3}\right)$, width of the fine-mode PSD $\left(3.8 \times 10^{-3} \pm 1.7 \times 10^{-3}\right)$, the surface reflectance at $354 \mathrm{~nm}$ $\left(3.4 \times 10^{-3} \pm 1.8 \times 10^{-3}\right)$ and $388 \mathrm{~nm}\left(2.8 \times 10^{-3} \pm 2.1 \times\right.$ $\left.10^{-1}\right)$, mean radius of the coarse-mode PSD $\left(3.1 \times 10^{-3} \pm\right.$ $\left.1.1 \times 10^{-3}\right)$, half width of the aerosol vertical distribution $\left(2.3 \times 10^{-3} \pm 1.5 \times 10^{-3}\right)$, mean radius of the fine-mode PSD 
$\left(1.1 \times 10^{-3} \pm 5.7 \times 10^{-4}\right)$, and width of the coarse-mode PSD $\left(8.7 \times 10^{-4} \pm 3.3 \times 10^{-4}\right)$ were smaller and that of the coarsemode $n_{\mathrm{r}}\left(5.2 \times 10^{-5} \pm 1.3 \times 10^{-4}\right)$ appeared to be negligible. The estimated $\varepsilon_{\mathrm{f}} \mathrm{S}$ of SSA were found to be about a factor of magnitude lower than the $\varepsilon_{\mathrm{sol}}$ of SSA. The mean values of $\varepsilon_{\mathrm{sm}}$ and $\varepsilon_{\mathrm{n}}$ of SSA were 0.023 and 0.029 , respectively. Thus, the estimated $\varepsilon_{\mathrm{sol}}$ of SSA at $388 \mathrm{~nm}$ is expected to be more reliable and represent the total uncertainties of SSA, since the uncertainty in SSA is predominantly affected by $\varepsilon_{\text {sol }}$, while uncertainty in AOT is affected by both $\varepsilon_{\text {sol }}$ and $\varepsilon_{\mathrm{f}}$. Note that the relative significances of the $\varepsilon_{\mathrm{f}} \mathrm{s}$ of retrievals depend on their condition. It is an additional merit of the error analysis using the $\mathrm{OE}$ method that it provides specific error estimates of individual target event retrieval (e.g., dust or biomass burning event). While analysis studies using satellite inversion products have often suffered from a lack of statistic reliability, more reliable error estimates in this study are expected to contribute to the assessment of significances of the analysis.

\section{Summary and discussion}

An OE-based aerosol retrieval and error characterization algorithm using the OMI near-UV radiances was developed in this study. The climatological values of OMAERUV products were employed as a priori data for the inversion method. The OE-based inversion method developed here not only provides the retrieved values of AOT and SSA, but also estimates of their uncertainties. The retrieved AOT and SSA at $388 \mathrm{~nm}$ were compared with the AERONET products during the DRAGON-NE Asia 2012 campaign. The retrieved AOT using the OE method showed better results than the operational product. The OE-based SSA at $388 \mathrm{~nm}$ showed consistency with AERONET inversion products comparable to that of the operational SSA. The estimated retrieval noise and smoothing error of OE-based AOT represented the variances of actual biases between the retrieved AOT and AERONET AOT well. The forward model parameter errors were analyzed separately for both AOT and SSA inversion products. Uncertainties of surface reflectance at $388 \mathrm{~nm}$, imaginary refractive index at $354 \mathrm{~nm}$, and number fine-mode fraction were found to be the most important parameters affecting the retrieval accuracy of AOT, while uncertainties in the real part refractive index of the coarse-mode PSD had a negligible effect. For SSA retrieval accuracy, number fine-mode fraction was found to be the most important parameter, while the other parameters appeared to have relatively small effects. As the FMF depends on the aerosol type, it is expected that more accurate aerosol-type classification might improve the retrieval accuracy of AOT and SSA. For AOT retrieval, the estimated $\varepsilon_{\mathrm{f}}$ was comparable with the $\varepsilon_{\text {sol }}$, while the $\varepsilon_{\mathrm{f}}$ of SSA was negligible compared to the $\varepsilon_{\text {sol }}$ of the retrieved SSA. It is also found that a sufficient amount of aerosol loading is necessary for reliable SSA retrieval.
However, there are still error sources which need to be analyzed, including the a priori error from climatology, aerosol morphology, cloud contamination, and three-dimensional effects of radiative transfer. The assumed conditions in the inversion procedure also differ from the real state. Validation studies for a longer period at more types of site are also necessary. Securing a more reliable a priori database is expected to improve the OE-based aerosol retrieval algorithm.

Acknowledgements. This research was supported by the GEMS program of the Ministry of Environment, Korea, and the Eco Innovation Program of KEITI (2012000160002). The authors also acknowledge the KNMI and NASA/GSFC for providing OMI and AERONET data, respectively. Authors also acknowledge all the P. I.s and staff for the contribution to the DRAGON-NE Asia campaign.

Edited by: P. Formenti

\section{References}

Ahn, C., Torres, O., and Bhartia, P. K.: Comparison of ozone monitoring instrument UV aerosol products with Aqua/Moderate Resolution Imaging Spectroradiometer and Multiangle Imaging Spectroradiometer observations in 2006, J. Geophys. Res.Atmos., 113, D16s27, doi:10.1029/2007jd008832, 2008.

Ahn, C., Torres, O., and Jethva, H.: Assessment of OMI near-UV aerosol optical depth over land, J. Geophys. Res.-Atmos., 119, 2457-2473, doi:10.1002/2013jd020188, 2014.

Al-Saadi, J., Szykman, J., Pierce, R. B., Kittaka, C., Neil, D., Chu, D. A., Remer, L., Gumley, L., Prins, E., Weinstock, L., MacDonald, C., Wayland, R., Dimmick, F., and Fishman, J.: Improving national air quality forecasts with satellite aerosol observations, B. Am. Meteorol. Soc., 86, 1249-1261, doi:10.1175/Bams-86-91249, 2005.

Breon, F. M., Tanre, D., and Generoso, S.: Aerosol effect on cloud droplet size monitored from satellite, Science, 295, 834-838, doi:10.1126/science.1066434, 2002.

Chahine, M. T.: Determination of temperature profile in an atmosphere from its outgoing radiance, J. Opt. Soc. Am., 12, 16341637, 1968.

Curier, R. L., Veefkind, J. P., Braak, R., Veihelmann, B., Torres, O., and de Leeuw, G.: Retrieval of aerosol optical properties from OMI radiances using a multiwavelength algorithm: Application to western Europe, J. Geophys. Res.-Atmos., 113, D17s90, doi:10.1029/2007jd008738, 2008.

de Graaf, M., Stammes, P., Torres, O., and Koelemeijer, R. B. A.: Absorbing Aerosol Index: Sensitivity analysis, application to GOME and comparison with TOMS, J. Geophys. Res.-Atmos., 110, D01201, doi:10.1029/2004jd005178, 2005.

Deuze, J. L., Breon, F. M., Devaux, C., Goloub, P., Herman, M., Lafrance, B., Maignan, F., Marchand, A., Nadal, F., Perry, G., and Tanre, D.: Remote sensing of aerosols over land surfaces from POLDER-ADEOS-1 polarized measurements, J. Geophys. Res.-Atmos., 106, 4913-4926, doi:10.1029/2000jd900364, 2001. 
Dobber, M. R., Dirksen, R. J., Levelt, P. F., Van den Oord, G. H. J., Voors, R. H. M., Kleipool, Q., Jaross, G., Kowalewski, M., Hilsenrath, E., Leppelmeier, G. W., de Vries, J., Dierssen, W., and Rozemeijer, N. C.: Ozone-Monitoring Instrument calibration, IEEE T. Geosci. Remote, 44, 1209-1238, doi:10.1109/Tgrs.2006.869987, 2006.

Dubovik, O.: Photopolarimetry in remote sensing, in: Mathematics, Physics and Chemistry, edited by: Videen, G., Yatskiv, Y., and Mishchenko, M., 2, Kluwer Academic Publishers, Netherlands, 65-106, 2004.

Dubovik, O. and King, M. D.: A flexible inversion algorithm for retrieval of aerosol optical properties from Sun and sky radiance measurements, J. Geophys. Res.-Atmos., 105, 20673-20696, doi:10.1029/2000jd900282, 2000.

Dubovik, O., Smirnov, A., Holben, B. N., King, M. D., Kaufman, Y. J., Eck, T. F., and Slutsker, I.: Accuracy assessments of aerosol optical properties retrieved from Aerosol Robotic Network (AERONET) Sun and sky radiance measurements, J. Geophys. Res.-Atmos., 105, 9791-9806, doi:10.1029/2000jd900040, 2000

Dubovik, O., Sinyuk, A., Lapyonok, T., Holben, B. N., Mishchenko, M., Yang, P., Eck, T. F., Volten, H., Munoz, O., Veihelmann, B., van der Zande, W. J., Leon, J. F., Sorokin, M., and Slutsker, I.: Application of spheroid models to account for aerosol particle nonsphericity in remote sensing of desert dust, J. Geophys. Res.Atmos., 111, D11208, doi:10.1029/2005jd006619, 2006.

Eyre, J. R.: On Systematic-Errors in Satellite Sounding Products and Their Climatological Mean-Values, Q. J. Roy. Meteor. Soc., 113, 279-292, doi:10.1256/Smsqj.47515, 1987.

Fisher, R. A.: On the "probable error" of a coefficient of correlation deduced from a small sample, Metron, 1, 3-32, 1921.

Fisher, D., Muller, J. P., and Yershov, V. N.: Automated Stereo Retrieval of Smoke Plume Injection Heights and Retrieval of Smoke Plume Masks From AATSR and Their Assessment With CALIPSO and MISR, IEEE T. Geosci. Remote, 52, 1249-1258, doi:10.1109/Tgrs.2013.2249073, 2014.

Govaerts, Y. M., Wagner, S., Lattanzio, A., and Watts, P.: Joint retrieval of surface reflectance and aerosol optical depth from MSG/SEVIRI observations with an optimal estimation approach: 1. Theory, J. Geophys. Res.-Atmos., 115, D02203, doi:10.1029/2009jd011779, 2010.

Herman, J. R., Bhartia, P. K., Torres, O., Hsu, C., Seftor, C., and Celarier, E.: Global distribution of UV-absorbing aerosols from Nimbus 7/TOMS data, J. Geophys. Res.-Atmos., 102, 1691116922, doi:10.1029/96jd03680, 1997.

Hess, M., Koepke, P., and Schult, I.: Optical properties of aerosols and clouds: The software package OPAC, B. Am. Meteorol. Soc., 79, 831-844, doi:10.1175/15200477(1998)079<0831:Opoaac>2.0.Co;2, 1998.

Holben, B. N., Eck, T. F., Slutsker, I., Tanre, D., Buis, J. P., Setzer, A., Vermote, E., Reagan, J. A., Kaufman, Y. J., Nakajima, T., Lavenu, F., Jankowiak, I., and Smirnov, A.: AERONET - A federated instrument network and data archive for aerosol characterization, Remote Sens. Environ., 66, 1-16, doi:10.1016/S00344257(98)00031-5, 1998

Jaross, G.: Disccusion of OMI BSDF calibration accuracy, in: Sources of systematic radiometric calibration accuracy of GEMS, edited by: Jeong, U., SSAI, Lanham, Maryland, USA, 2015.
Jeong, U., Kim, J., Lee, H., Jung, J., Kim, Y. J., Song, C. H., and Koo, J. H.: Estimation of the contributions of long range transported aerosol in East Asia to carbonaceous aerosol and PM concentrations in Seoul, Korea using highly time resolved measurements: a PSCF model approach, J. Environ. Monitor., 13, 19051918, doi:10.1039/C0em00659a, 2011.

Jethva, H. and Torres, O.: Satellite-based evidence of wavelengthdependent aerosol absorption in biomass burning smoke inferred from Ozone Monitoring Instrument, Atmos. Chem. Phys., 11, 10541-10551, doi:10.5194/acp-11-10541-2011, 2011.

Jethva, H., Torres, O., and Ahn, C.: Global assessment of OMI aerosol single-scattering albedo using ground-based AERONET inversion, J. Geophys. Res.-Atmos., 119, 9020 9040, doi:10.1002/2014jd021672, 2014.

Kalman, R. E.: A new approach to linear filtering and prediction problems, J. Basic Eng.-T. ASME, 82, 35-45, 1960.

Kim, J., Lee, J., Lee, H. C., Higurashi, A., Takemura, T., and Song, C. H.: Consistency of the aerosol type classification from satellite remote sensing during the Atmospheric Brown Cloud-East Asia Regional Experiment campaign, J. Geophys. Res.-Atmos., 112, D22s33, doi:10.1029/2006jd008201, 2007.

Kinne, S., Schulz, M., Textor, C., Guibert, S., Balkanski, Y., Bauer, S. E., Berntsen, T., Berglen, T. F., Boucher, O., Chin, M., Collins, W., Dentener, F., Diehl, T., Easter, R., Feichter, J., Fillmore, D., Ghan, S., Ginoux, P., Gong, S., Grini, A., Hendricks, J., Herzog, M., Horowitz, L., Isaksen, I., Iversen, T., Kirkevåg, A., Kloster, S., Koch, D., Kristjansson, J. E., Krol, M., Lauer, A., Lamarque, J. F., Lesins, G., Liu, X., Lohmann, U., Montanaro, V., Myhre, G., Penner, J., Pitari, G., Reddy, S., Seland, O., Stier, P., Takemura, T., and Tie, X.: An AeroCom initial assessment - optical properties in aerosol component modules of global models, Atmos. Chem. Phys., 6, 1815-1834, doi:10.5194/acp-6-1815-2006, 2006.

Kirchstetter, T. W., Novakov, T., and Hobbs, P. V.: Evidence that the spectral dependence of light absorption by aerosols is affected by organic carbon, J. Geophys. Res.-Atmos., 109, D21208, doi:10.1029/2004jd004999, 2004.

Lee, J., Kim, J., Yang, P., and Hsu, N. C.: Improvement of aerosol optical depth retrieval from MODIS spectral reflectance over the global ocean using new aerosol models archived from AERONET inversion data and tri-axial ellipsoidal dust database, Atmos. Chem. Phys., 12, 7087-7102, doi:10.5194/acp-12-70872012, 2012.

Levelt, P. F., Van den Oord, G. H. J., Dobber, M. R., Malkki, A., Visser, H., de Vries, J., Stammes, P., Lundell, J. O. V., and Saari, H.: The Ozone Monitoring Instrument, IEEE T. Geosci. Remote, 44, 1093-1101, doi:10.1109/Tgrs.2006.872333, 2006.

Levy, R. C., Remer, L. A., Mattoo, S., Vermote, E. F., and Kaufman, Y. J.: Second-generation operational algorithm: Retrieval of aerosol properties over land from inversion of Moderate Resolution Imaging Spectroradiometer spectral reflectance, J. Geophys. Res.-Atmos., 112, D13211, doi:10.1029/2006jd007811, 2007.

Lin, J.-T., Martin, R. V., Boersma, K. F., Sneep, M., Stammes, P., Spurr, R., Wang, P., Van Roozendael, M., Clémer, K., and Irie, H.: Retrieving tropospheric nitrogen dioxide from the Ozone Monitoring Instrument: effects of aerosols, surface reflectance anisotropy, and vertical profile of nitrogen dioxide, Atmos. Chem. Phys., 14, 1441-1461, doi:10.5194/acp-14-1441-2014, 2014. 
Livingston, J. M., Redemann, J., Russell, P. B., Torres, O., Veihelmann, B., Veefkind, P., Braak, R., Smirnov, A., Remer, L., Bergstrom, R. W., Coddington, O., Schmidt, K. S., Pilewskie, P., Johnson, R., and Zhang, Q.: Comparison of aerosol optical depths from the Ozone Monitoring Instrument (OMI) on Aura with results from airborne sunphotometry, other space and ground measurements during MILAGRO/INTEX-B, Atmos. Chem. Phys., 9, 6743-6765, doi:10.5194/acp-9-6743-2009, 2009.

Mishchenko, M. I. and Travis, L. D.: T-Matrix Computations of Light-Scattering by Large Spheroidal Particles, Opt. Commun., 109, 16-21, doi:10.1016/0030-4018(94)90731-5, 1994.

Mishchenko, M. I., Lacis, A. A., Carlson, B. E., and Travis, L. D.: Nonsphericity of Dust-Like Tropospheric Aerosols - Implications for Aerosol Remote-Sensing and Climate Modeling, Geophys. Res. Lett., 22, 1077-1080, doi:10.1029/95g100798, 1995.

Mishchenko, M. I., Travis, L. D., Kahn, R. A., and West, R. A.: Modeling phase functions for dustlike tropospheric aerosols using a shape mixture of randomly oriented polydisperse spheroids, J. Geophys. Res.-Atmos., 102, 16831-16847, doi:10.1029/96jd02110, 1997.

Mishchenko, M. I., Geogdzhayev, I. V., Liu, L., Ogren, J. A., Lacis, A. A., Rossow, W. B., Hovenier, J. W., Volten, H., and Munoz, O.: Aerosol retrievals from AVHRR radiances: effects of particle nonsphericity and absorption and an updated long-term global climatology of aerosol properties, J. Quant. Spectrosc. Ra., 79, 953-972, doi:10.1016/S0022-4073(02)00331-X, 2003.

Palmer, P. I., Jacob, D. J., Chance, K., Martin, R. V., Spurr, R. J. D., Kurosu, T. P., Bey, I., Yantosca, R., Fiore, A., and Li, Q. B.: Air mass factor formulation for spectroscopic measurements from satellites: Application to formaldehyde retrievals from the Global Ozone Monitoring Experiment, J. Geophys. Res.-Atmos., 106, 14539-14550, doi:10.1029/2000jd900772, 2001.

Phillips, B. L.: A technique for numerical solution of certain intergral equation of first kind, J. Assoc. Comput. Mach., 9, 84-97, 1962.

Ramanathan, V., Crutzen, P. J., Kiehl, J. T., and Rosenfeld, D.: Atmosphere - Aerosols, climate, and the hydrological cycle, Science, 294, 2119-2124, doi:10.1126/science.1064034, 2001.

Rodgers, C. D.: Characterization and Error Analysis of Profiles Retrieved from Remote Sounding Measurements, J. Geophys. Res.Atmos., 95, 5587-5595, doi:10.1029/Jd095id05p05587, 1990.

Rodgers, C. D.: Inverse method for atmospheric sounding: theory and practice, World Scientific Publishing Co. Pte. Ltd., Singapore, 2000.

Russell, P. B., Hobbs, P. V., and Stowe, L. L.: Aerosol properties and radiative effects in the United States East Coast haze plume: An overview of the Tropospheric Aerosol Radiative Forcing Observational Experiment (TARFOX), J. Geophys. Res.-Atmos., 104, 2213-2222, doi:10.1029/1998jd200028, 1999.

Russell, P. B., Bergstrom, R. W., Shinozuka, Y., Clarke, A. D., DeCarlo, P. F., Jimenez, J. L., Livingston, J. M., Redemann, J., Dubovik, O., and Strawa, A.: Absorption Angstrom Exponent in AERONET and related data as an indicator of aerosol composition, Atmos. Chem. Phys., 10, 1155-1169, doi:10.5194/acp-101155-2010, 2010.

Spurr, R. and Christi, M.: On the generation of atmospheric property Jacobians from the (V)LIDORT linearized radia- tive transfer models, J. Quant. Spectrosc. Ra., 142, 109-115, doi:10.1016/j.jqsrt.2014.03.011, 2014.

Spurr, R., Wang, J., Zeng, J., and Mishchenko, M. I.: Linearized T-matrix and Mie scattering computations, J. Quant. Spectrosc. Ra., 113, 425-439, doi:10.1016/j.jqsrt.2011.11.014, 2012.

Spurr, R. J. D.: VLIDORT: A linearized pseudo-spherical vector discrete ordinate radiative transfer code for forward model and retrieval studies in multilayer multiple scattering media, J. Quant. Spectrosc. Ra., 102, 316-342, doi:10.1016/j.jqsrt.2006.05.005, 2006.

Tikhonov, A. N.: On the solution of incorrectly stated problems and a method of regularization, Dokl. Akad. Nauk., 151, 501-504, 1963.

Torres, O., Bhartia, P. K., Herman, J. R., Ahmad, Z., and Gleason, $\mathrm{J}$.: Derivation of aerosol properties from satellite measurements of backscattered ultraviolet radiation: Theoretical basis (vol. 103, p. 17099, 1998), J. Geophys. Res.-Atmos., 103, 23321-23321, 1998.

Torres, O., Bhartia, P. K., Herman, J. R., Sinyuk, A., Ginoux, P., and Holben, B.: A long-term record of aerosol optical depth from TOMS observations and comparison to AERONET measurements, J. Atmos. Sci., 59, 398-413, doi:10.1175/15200469(2002)059<0398:Altroa>2.0.Co;2, 2002a.

Torres, O., Decae, R., Veefkind, J. P., and de Leeuw, G.: OMI aerosol retrieval algorithm, in OMI Algorithm Theoretical Basis Document, NASA Goddard Space Flight Cent., Greenbelt, Md., USA, 47-71, 2002b.

Torres, O., Bhartia, P. K., Sinyuk, A., Welton, E. J., and Holben, B.: Total Ozone Mapping Spectrometer measurements of aerosol absorption from space: Comparison to SAFARI 2000 groundbased observations, J. Geophys. Res.-Atmos., 110, D10s18, doi:10.1029/2004JD004611, 2005.

Torres, O., Tanskanen, A., Veihelmann, B., Ahn, C., Braak, R., Bhartia, P. K., Veefkind, P., and Levelt, P.: Aerosols and surface UV products from Ozone Monitoring Instrument observations: An overview, J. Geophys. Res.-Atmos., 112, D24s47, doi:10.1029/2007jd008809, 2007.

Torres, O., Ahn, C., and Chen, Z.: Improvements to the OMI nearUV aerosol algorithm using A-train CALIOP and AIRS observations, Atmos. Meas. Tech., 6, 3257-3270, doi:10.5194/amt-63257-2013, 2013.

Twomey, S.: On the numerical solution of Fredholm integral equations of the first kind by the inversion of the linear system produced by quadrature, J. Assoc. Comput. Mach., 10, 97-101, 1963.

Veihelmann, B., Levelt, P. F., Stammes, P., and Veefkind, J. P.: Simulation study of the aerosol information content in OMI spectral reflectance measurements, Atmos. Chem. Phys., 7, 3115-3127, doi:10.5194/acp-7-3115-2007, 2007.

Wagner, S. C., Govaerts, Y. M., and Lattanzio, A.: Joint retrieval of surface reflectance and aerosol optical depth from MSG/SEVIRI observations with an optimal estimation approach: 2 . Implementation and evaluation, J. Geophys. Res.-Atmos., 115, D02204, doi:10.1029/2009jd011780, 2010.

Wurl, D., Grainger, R. G., McDonald, A. J., and Deshler, T.: Optimal estimation retrieval of aerosol microphysical properties from SAGE II satellite observations in the volcanically unperturbed lower stratosphere, Atmos. Chem. Phys., 10, 4295-4317, doi:10.5194/acp-10-4295-2010, 2010. 
Young, S. A., Vaughan, M. A., Kuehn, R. E., and Winker, D. M.: The Retrieval of Profiles of Particulate Extinction from CloudAerosol Lidar and Infrared Pathfinder Satellite Observations (CALIPSO) Data: Uncertainty and Error Sensitivity Analyses, J. Atmos. Ocean. Tech., 30, 395-428, doi:10.1175/Jtech-D-1200046.1, 2013. 